\title{
Major changes of cell function and toxicant sensitivity in cultured cells undergoing mild, quasi-natural genetic drift
}

\author{
Simon Gutbier ${ }^{1} \cdot$ Patrick May $^{2} \cdot$ Sylvie Berthelot ${ }^{1} \cdot$ Abhimanyu Krishna $^{2} \cdot$ Timo Trefzer $^{1} \cdot$ Mehri Behbehani $^{1}$. \\ Liudmila Efremova ${ }^{1} \cdot$ Johannes Delp ${ }^{1} \cdot$ Gerhard Gstraunthaler $^{3} \cdot$ Tanja Waldmann $^{1} \cdot$ Marcel Leist $^{1}$
}

Received: 17 April 2018 / Accepted: 19 June 2018 / Published online: 8 October 2018

(c) The Author(s) 2018

\begin{abstract}
Genomic drift affects the functional properties of cell lines, and the reproducibility of data from in vitro studies. While chromosomal aberrations and mutations in single pivotal genes are well explored, little is known about effects of minor, possibly pleiotropic, genome changes. We addressed this question for the human dopaminergic neuronal precursor cell line LUHMES by comparing two subpopulations (SP) maintained either at the American-Type-Culture-Collection (ATCC) or by the original provider (UKN). Drastic differences in susceptibility towards the specific dopaminergic toxicant 1-methyl4-phenylpyridinium (MPP+) were observed. Whole-genome sequencing was performed to identify underlying genetic differences. While both SP had normal chromosome structures, they displayed about 70 differences on the level of amino acid changing events. Some of these differences were confirmed biochemically, but none offered a direct explanation for the altered toxicant sensitivity pattern. As second approach, markers known to be relevant for the intended use of the cells were specifically tested. The "ATCC" cells rapidly down-regulated the dopamine-transporter and tyrosine-hydroxylase after differentiation, while "UKN" cells maintained functional levels. As the respective genes were not altered themselves, we conclude that polygenic complex upstream changes can have drastic effects on biochemical features and toxicological responses of relatively similar SP of cells.
\end{abstract}

Keywords Human genome $\cdot$ Cell stability $\cdot$ Dopamine transporter, genome comparison, genotype-phenotype correlation

\section{Introduction}

Cell lines, as biological material essential for many research fields, are difficult to define and standardize (Hartung and Leist 2008; Nims and Reid 2017). Methods like short tandem repeat quantification (STR) can show whether two cells are derived from the same donor (Bian et al. 2017), and

Electronic supplementary material The online version of this article (https://doi.org/10.1007/s00204-018-2326-5) contains supplementary material, which is available to authorized users.

Marcel Leist

Marcel.Leist@uni-konstanz.de

1 Department for in vitro toxicology and biomedicine (Doerenkamp-Zbinden chair), University of Konstanz, PO Box M657, 78457 Konstanz, Germany

2 Luxembourg Centre for Systems Biomedicine, University of Luxembourg, Esch-sur-Alzette, Luxembourg

3 Division of Physiology, Innsbruck Medical University, Schöpfstraße 41/1, 6020 Innsbruck, Austria classic cytogenetic approaches can provide data on genome integrity at the level of chromosomes or large fragments thereof. Sequencing methods that map individual base pairs (bp) additionally identify small copy number variations (CNVs; $1 \mathrm{kbp}-3 \mathrm{Mbp}$ ), larger structural variants (SV; > 3 $\mathrm{Mbp}$ ) and mutations or single nucleotide variants (SNV). Such genome alterations continuously occur in somatic cells at relatively high frequency (Gore et al. 2011; Laurent et al. 2011; Milholland et al. 2017; Youssoufian and Pyeritz 2002), and may often be without functional consequences. This background "genetic noise" makes it difficult to identify changes that affect biological features of interest. Distinguishing relevant changes from background noise of genome alternations is important to the question of whether two subpopulations (SP) of cells are functionally identical. Many fields in fundamental and applied sciences, where cells are the essential material to derive information or to generate bio-products, strongly rely on defining methods for determining identity of the used cells. 
Even with apparently clear cell identity established (e.g. by STR profiling), large genetic variations, such as amplification or loss of chromosomal parts, may go undetected, and apparently identical cells may indeed be genetically diverse (Kleensang et al. 2016; Milholland et al. 2017). For instance, some pluripotent stem cell lines tend to develop aneuploidy or translocations during prolonged culture: trisomy 12 or X, and amplification of $17 \mathrm{q}$ provide selection advantages by multiplication of stemness or anti-apoptotic genes (Baker et al. 2016; Martins-Taylor and Xu 2012). Also, it is well established that for cell lines like HeLa, many genetically different SP exist (Frattini et al. 2015). On an even more subtle level, cell identity may be affected by small mutations, and SNP profiling is one of the approaches to document such changes (Miller et al. 2014). Next-generation sequencing methods opened the possibility for a closer genetic characterization [by whole-genome sequencing (WGS)] at the bp level (Baker et al. 2016; Krishna et al. 2014; Milholland et al. 2017). By comparing differences in the sequence of a cellular genome to the reference genome, single nucleotide variants (SNV; small deletions, insertions or base exchanges in the range of few nucleotides), $\mathrm{CNV}$ (sequence parts larger than 1000 bps that show an average ploidy of $>2$ or $<2$ ) and other changes can be detected. Typically, around 3.5-4 million SNVs may be detected for iPSC cell lines compared to the reference genome. After removal of already known SNVs, 1000-2000 SNVs are typically identified between cell lines. These are predominantly heterozygous, and only 5-12 are then expected in coding regions of genes (Cheng et al. 2012; Gore et al. 2011). Notably, also genome changes that do not alter the protein structures may have drastic functional consequences. For instance, CNVs have been associated with neurological and psychiatric disorders (Cai et al. 2015; McConnell et al. 2013; Stefansson et al. 2014).

Studies using WGS point out two factors that favor generation of genetically distinct subpopulations (SP) upon prolonged culture. The first relates to genetic heterogeneity of starting cultures, containing genetically distinct subpopulations (Cai et al. 2014). Second, genetic variants might arise de-novo during sub-culturing and be selected by further propagation of the cell line. In neuronal precursor cells, a potential additional mechanism responsible for the genome dynamics are L1 retrotransposons, which are highly active during neurodevelopment (Coufal et al. 2009), and may cause insertional mutagenesis.

LUHMES cells, examined in this study, are neural precursor cells of the mesencephalon, obtained from an 8-weekold fetus. They were conditionally immortalized with a tetracycline-controlled v-myc transgene (Lotharius et al. 2002, 2005). Its down-regulation triggers the differentiation to electrically active dopaminergic, fully post-mitotic neurons (Scholz et al. 2011). LUHMES have been deposited in 2006 at the American Type Culture Collection (ATCC)
(Reid 2017), and a recent report using the banked cells (Zhang et al. 2014) found that they tolerate up to $60 \mu \mathrm{M}$ of the neurotoxicant 1-methyl-4-phenylpyridinium $\left(\mathrm{MPP}^{+}\right)$, while cells from the original provider laboratory (UKN) died at 3-5 $\mu \mathrm{M}$ (Krug et al. 2014; Poltl et al. 2012; Schildknecht et al. 2009). This large shift in toxicological properties called for a comparative investigation of the cells. As strategies to define functional cell identity are of vast general importance, we explored WGS as a novel approach (Kaas et al. 2015; Seim et al. 2017). Previous studies addressing genetic drift focused mainly on the genome changes arising during prolonged culture. Only little quantitative information is available on how such genetic drift effects cell function. We addressed here the question on whether genome analysis can comprehensively and unambiguously define cell identity relative to some well-defined functions. Our results suggest that a prediction of functionality requires more than the genome data, and that cell identity definition needs to follow a fit-for-purpose definition, which mostly requires specifically adopted analytical endpoints.

\section{Materials and methods}

\section{Chemicals}

Dibutyryl-cAMP (cAMP), fibronectin, Hoechst dye H-33342, resazurin sodium salt, tetracycline, tetramethylrhodamine ethyl ester (TMRE) and $\mathrm{MPP}^{+}$were from Sigma (Steinheim, Germany). Recombinant human FGF-2 and recombinant human glial cell derived neurotrophic factor (GDNF) were from R\&D Systems (Minneapolis). Tween-20 and sodium dodecyl sulfate (SDS) were from Roth (Karlsruhe, Germany). All culture reagents were from Gibco/Fisher scientific (Hampton, New Hampshire, USA) unless otherwise specified.

\section{Cell culture}

Handling of LUHMES human neuronal precursor cells was performed exactly as previously described in detail (Schildknecht et al. 2013; Scholz et al. 2011). Briefly, maintained in a $5 \% \mathrm{CO}_{2} / 95 \%$ air atmosphere at $37{ }^{\circ} \mathrm{C}$ in proliferation medium (PM), consisting of advanced DMEM/F12 with $2 \mathrm{mM}$ L-glutamine, $1 \times \mathrm{N} 2$ supplement (Invitrogen), and $40 \mathrm{ng} / \mathrm{ml}$ FGF-2, cells were passaged three times a week. For differentiation, 8 million cells were seeded in a Nunclon T175 tissue culture flask in PM. After $24 \mathrm{~h}$, the medium was changed to differentiation medium (DM), consisting of advanced DMEM/F12 supplemented with $2 \mathrm{mM}$ L-glutamine, $1 \times \mathrm{N} 2,2.25 \mu \mathrm{M}$ tetracycline (to switch off the transgene), $1 \mathrm{mM}$ dibutyryl $3{ }^{\prime}, 5^{\prime}$-cyclic adenosine monophosphate (cAMP) and $2 \mathrm{ng} / \mathrm{ml}$ GDNF. $48 \mathrm{~h}$ later, 
cells were trypsinized, and seeded in a density of $1.5 \times 10^{5}$ cells $/ \mathrm{cm}^{2}$ on dishes precoated with $50 \mu \mathrm{g} / \mathrm{ml}$ poly-L-ornithine (PLO) and $1 \mu \mathrm{g} / \mathrm{ml}$ fibronectin in DM. On day 4 of differentiation (d4), the medium was exchanged for fresh DM.

\section{Cell viability measurement}

Resazurin Metabolic activity was detected by a resazurin assay (Schildknecht et al. 2009). Briefly, resazurin solution was added to the cell culture medium to obtain a final concentration of $10 \mu \mathrm{g} / \mathrm{ml}$. After incubation for $30 \mathrm{~min}$ at $37{ }^{\circ} \mathrm{C}$, the fluorescence signal was measured at an excitation wavelength of $530 \mathrm{~nm}$, using a $590 \mathrm{~nm}$ long-pass filter to record the emission. Fluorescence values were normalized by setting fluorescence values of untreated wells as $100 \%$.

$L D H$ release $\mathrm{LDH}$ activity was detected separately in the supernatant and cell homogenate as described earlier (Latta et al. 2000). The ratio of $\mathrm{LDH}_{\text {supernatant }} / \mathrm{LDH}_{\text {supernatant+ cell lysate }}$ was calculated and expressed in percent (Latta et al. 2000).

\section{Neurite area detection}

Labeling live cells was performed with $1 \mu \mathrm{M}$ calcein$\mathrm{AM} / 1 \mu \mathrm{g} / \mathrm{ml} \mathrm{H}-33342$ for $30 \mathrm{~min}$ at $37{ }^{\circ} \mathrm{C}$. Images were collected in two different fluorescent channels using an automated microscope (Array-Scan VTI HCS Reader, Thermo Fisher, PA, USA) with high content imaging software (vHCS SCAN, Thermo Fisher, PA, USA). For visualization, an Olympus IX81 inverted epifluorescence microscope with a $20 \times$ objective was used. Nuclei were automatically identified in channel $1(365 \pm 50 / 461 \pm 15 \mathrm{~nm})$ as objects according to their size, area, shape, and intensity. The calcein signal was detected in channel $2(475 \pm 40 / 525 \pm 15 \mathrm{~nm})$. An algorithm quantified all calcein positive cells as viable and nuclei stained by H-33342 only as "non viable" cells.

For quantification of the neurite area of $\mathrm{d} 3$ cells a wellestablished algorithm was applied (Stiegler et al. 2011). For d6 LUHMES, cells were fixed and stained for $\beta$-III-tubulin and $\mathrm{H}-33342$, and then the same algorithm was applied.

\section{ATP determination}

To determine intracellular ATP, cells grown in 24-well plates were scratched and sonicated in PBS-buffer and boiled at $95{ }^{\circ} \mathrm{C}$ for $10 \mathrm{~min}$ followed by centrifugation at $10,000 \mathrm{~g}$ for 5 min for the removal of cell debris (Volbracht et al. 1999, 2001). For the detection of ATP levels, a commercially available ATP assay reaction mixture (Sigma, Steinheim, Germany), containing luciferin and luciferase, was used. $50 \mu \mathrm{l}$ sample and $100 \mu \mathrm{l}$ of assay-mix were added to a black 96-well plate. Standards were prepared by serial dilutions of ATP disodium salt hydrate (Sigma, Steinheim, Germany) to obtain final concentrations ranging from $1000 \mathrm{nM}$ to $7.8 \mathrm{nM}$.

\section{GSH determination}

For glutathione determination cells were washed with PBS and lysed in $400 \mu \mathrm{l}$ of $1 \%$ sulfosalicylic acid (w/v). The lysates were collected, sonicated 5 times and centrifuged at $12,000 \times g$ for $5 \mathrm{~min}$ at $4{ }^{\circ} \mathrm{C}$ to remove cell debris. Total glutathione content was determined by a DTNB [5,5'-dithiobis(2-nitrobenzoic acid)] reduction assay. $20 \mu \mathrm{l}$ sample was mixed with $180 \mu \mathrm{l}$ assay mixture containing $300 \mu \mathrm{M}$ DTNB, $1 \mathrm{U} / \mathrm{ml}$ glutathione-reductase, $400 \mu \mathrm{M}$ NADPH, $1 \mathrm{mM}$ EDTA in $100 \mathrm{mM}$ sodium phosphate buffer, pH 7.5 (all Sigma, Steinheim, Germany). DTNB reduction was measured photometrically at $405 \mathrm{~nm}$ in $5 \mathrm{~min}$ intervals over $30 \mathrm{~min}$. GSH standard curves were performed by serial dilutions ranging from $1000 \mathrm{nM}$ to $7.8 \mathrm{nM}$, respectively.

\section{Western blot analysis}

Cells were lysed in RIPA-buffer (50 mM Tris-base, $150 \mathrm{mM}$ $\mathrm{NaCl}, 1 \mathrm{mM}$ EDTA, $0.25 \%$ sodium deoxycholate, $1 \%$ NP40, $1 \mathrm{mM} \mathrm{Na} 3 \mathrm{VO} 4,50 \mathrm{mM} \mathrm{NaF}, \mathrm{pH}$ 7.5) containing $1 \times$ protease inhibitor (Roche) and $0.5 \%$ phosphatase inhibitor cocktail 2 (Sigma, Steinheim, Germany). Determination of protein concentration was performed using a BCA protein assay kit (Pierce/Thermo Fisher Scientific, Rockford, IL, USA). Thirty-five $\mu \mathrm{g}$ of total protein were loaded onto $12 \%$ SDS gels. Proteins were transferred onto nitrocellulose membranes (Amersham, Buckinghamshire, UK). Loading and transfer were checked by brief Ponceau staining. Washed membranes were blocked with or 5\% BSA in TBS-Tween $(0.1 \%)$ for $1 \mathrm{~h}$. Primary antibodies were incubated at $4{ }^{\circ} \mathrm{C}$ overnight. Following washing steps with TBS-Tween $(0.1 \%)$, horseradish peroxidase-conjugated secondary antibodies were incubated for $1 \mathrm{~h}$ at RT. For visualization, ECL Western blotting substrate (Pierce/Thermo Fisher Scientific, Rockford, IL, USA) was used (Gerhardt et al. 2001).

\section{Immunocytochemistry}

Cells were grown on $13 \mathrm{~mm}$ glass coverslips (Menzel, Braunschweig, Germany) in 24-well plastic cell culture plates (NunclonTM) and fixed with 4\% paraformaldehyde (Hansson et al. 2000; Hirt et al. 2000). After incubation with the primary antibody overnight (see Table. S1) and with the appropriate secondary antibody for $1 \mathrm{~h}$, Hoechst-33342 $(1 \mu \mathrm{g} / \mathrm{ml})$ was added for $10 \mathrm{~min}$ prior to the final washing step. Coverslips were mounted on glass slides with Fluorsave reagent (Calbiochem/Merck/Darmstadt, Germany).

\section{EdU incorporation}

Cells were grown and differentiated on coated glass coverslips and fixed with PBS, $4 \%$ paraformaldehyde, $2 \%$ 
sucrose for $15 \mathrm{~min}$. For EdU-staining cells were incubated with $10 \mu \mathrm{M}$ EdU 30 min previous to fixation. To detect EdU incorporation the Click-iT ${ }^{\circledR}$ EdU Alexa Fluor ${ }^{\circledR} 555$ Imaging Kit from Life Technologies (Carlsbad, CA, USA) was used as described by the provider. For the quantitative image analysis, we used KNIME Image Processing Extension (Version 1.1.2). KNIME (Konstanz Information Miner) (https://www. knime.com/) is a user-friendly and comprehensive opensource data integration, processing, analysis, and exploration platform designed to handle large amounts of heterogeneous data. The Image Processing Extension (http://tech. knime.org/community/image-processing) of KNIME allows the documentation of the Image Analysis steps in a so-called workflow. Total nuclei and EdU positive nuclei were counted automatically.

\section{Quantitative real-time PCR (qPCR)}

For reverse transcription quantitative PCR analysis, RNA was extracted with the PureLink RNA mini Kit (Invitrogen, Darmstadt, Germany) according to the manufacturer's instructions. For transcript analyses of LUHMES, primers (Eurofins MWG Operon, Ebersberg, Germany) were designed using $\mathrm{AiO}$ (All in One) bioinformatics software (Karreman 2002) and can be found in Table S2. All RTqPCRs were based on the SsoFast EvaGreen detection system and were run in a CFX96 Cycler (Biorad, München, Germany) and analyzed with Biorad iCycler software (Balmer et al. 2012; Zimmer et al. 2011a). The threshold cycles $\left(C_{\mathrm{t}}\right)$ were determined for each gene and gene expression levels were calculated as relative expression compared to GAPDH $\left(2^{-(\Delta C t)}\right)$ or as fold change relative to control $\left(2^{-(\Delta \Delta C \mathrm{t})}\right) . \Delta C_{\mathrm{t}}$ and $\Delta \Delta C_{\mathrm{t}}$ were calculated using the following formulas:

- $\Delta C_{\mathrm{t}}=C_{\mathrm{t}}($ condition $\mathrm{X} /$ gene $\mathrm{Y})-C_{\mathrm{t}}($ condition $\mathrm{X} /$ GAPDH)

$$
\begin{aligned}
\Delta \Delta C_{\mathrm{t}}= & \Delta C_{\mathrm{t}}(\text { condition } \mathrm{X} / \text { gene } \mathrm{Y}) \\
& -\Delta C_{\mathrm{t}}(\text { untreated control } / \text { gene } \mathrm{Y}) .
\end{aligned}
$$

\section{Dopamine measurement}

Predifferentiated LUHMES cells (d2) were seeded in T75 Nuclon Flask and differentiated according to the protocol. On day 6 , cells were lysed in $0.2 \%$ Triton X-100, $0.01 \mathrm{M}$ $\mathrm{HCl}, 1 \mathrm{mM}$ EDTA, $4 \mathrm{mM}$ sodium metabisulfite and $1 \mathrm{mM}$ Ascorbate. Cells were scraped with a cell scraper, sonicated, centrifuged at $3000 \mathrm{~g}$ for $5 \mathrm{~min}$ and supernatants were frozen at $-20{ }^{\circ} \mathrm{C}$. The dopamine content in cell lysates was analyzed using Dopamine ELISA Kit (Abnova) according to the manufacturer's protocol.

\section{${ }^{3} \mathrm{H}-\mathrm{MPP}+$ uptake}

Cells were incubated with $5 \mu \mathrm{M}^{1} \mathrm{H}-\mathrm{MPP}^{+}$and $0.125 \mu \mathrm{Ci}$ per $200 \mu \mathrm{l}(15 \mathrm{nM})$ volume radioactively labeled ${ }^{3} \mathrm{H}-\mathrm{MPP}^{+}$ at $37^{\circ} \mathrm{C}$ for different incubation times. The supernatant and the cells were separated. Cells were washed 3 times in PBS and then mechanically removed from the multiwell plate in an equal volume PBS. $2 \mathrm{ml}$ Ultima Gold AB solution was added to the supernatant and lysed cells. Light emission was measured by Beckman LS 6500 scintillation counter (Schildknecht et al. 2015; Zimmer et al. 2011b).

\section{Sequencing and genome comparison}

DNA was prepared from the "UKN" and "ATCC" LUHMES (ATC CRL-2927) SP using the Gentra Puregene Cell kit (Qiagen; Venlo, Netherlands). After sequencing, the reads (about 30× full genome coverage) were mapped against the NCBI Build 37.2 reference genome (Table S3). The "UKN" SP was paired-end sequenced with Complete Genomics (CG), Inc (Mountain View, CA, USA), using their proprietary sequencing-by-ligation technology (Drmanac et al. 2010). CG performed primary data analysis as part of their Standard Sequencing Service pipeline (v 2.4.0.43), including image analysis, base calling, quality control, mapping and variant calling. The CG pipeline calls different types of variants with independent pipelines including small SNVs and insertions and deletions (indels), copy number variants $(\mathrm{CNV})$, structural variants $(\mathrm{SV})$ and mobile element insertions (MEI). "ATCC" SP was paired-end sequenced $(2 \times 150 \mathrm{bp})$ with the Illumina FastTrack Service. Library preparation was performed using the TruSeq Nano DNA kit (Illumina), and processed with the Illumina pipeline version v4.0.2 using the Isaac Aligner (6.15.01) for mapping, Isaac Variant Caller (2.1.4) for calling germline SNVs and indels, the Isaac CNV Caller (1.1.0) for germline CNV calls (Raczy et al. 2013), and Isaac SV caller (0.23.1).

\section{Definitions of calls}

The significant differences from the reference genome (=calls) were categorized as follows: CNV were called using coverage data from both WGS and a human reference genome bin-size of $\approx 1 \mathrm{kbp}$ resolution. They were defined as parts of the genome larger than $1000 \mathrm{bp}$ and with an average ploidy of $>2$ or $<2$. SV were defined as rearrangements in the genome structure that affect a sequence length ranging from $1 \mathrm{~kb}$ to $3 \mathrm{Mb}$, such as large deletions, duplications and inversions. SNV were defined as single nucleotide exchanges. While small insertions and deletions are subsequently called indels ( $\max$ size: $50 \mathrm{bp}$ ). For CG, SNV and indels were derived from the "var file". CNV calls were taken from cnvSegmentsNondiploidBeta-* file and 
high-confidence structural variation, SV events were taken from /highConfidenceSvEventsBeta-* file and MEI from the mobileElementInsertionsBeta-* file. For Illumina, SNV and indels, $\mathrm{CNV}$ and $\mathrm{SV}$ were extracted from the different VCF files.

SNV from both platforms were combined into CG testvariant format and compared using custom perl/python scripts. For CG data, coverage statistics were derived from coverage and coverageRefScore files for each chromosome. Coverage at every base was assessed directly from these files. For Illumina, coverage information was extracted directly from BAM (Binary Sequence Alignment format) files. ANNOVAR (Wang et al. 2010) (v20150322) was used to annotate the SNV, SV and CNV with RefSeq and Ensembl gene annotations.

\section{Genetic identity analysis of ATCC and UKN LUHMES genomes}

To compare the genetic identity of both LUHMES SP, the PLINK software (Purcell et al. 2007) was used. PLINK is designed to identify kinship levels in genomes based on the comparison of chromosome stretches that show identity-bydescent (IBD). IBD DNA segments share a common ancestor, i.e. they are identical-by-state (IBS) and lack recombination events in the corresponding sequence. Two individuals can share 0,1 or 2 alleles referring then to $I B D=0, I B D=1$ and $I B D=2$, respectively. IBD was determined on the basis of common SNVs and small indels from the HapMap project (downloaded from the Broad resource bundle as part of the GATK toolkit: https://www.broadinstitute.org/gatk/ guide/article.php?id=1213). The SNVs and indels called in both genomes were used for IBD analysis. As measure of similarity, we used the so-called PI_HAT score, that ranges from 0 (no relationship) to 1 (identity across the genome), and which is calculated from a weighted sum of probabilities for a large number of genome segments to be IBD [PI_ $\left.\mathrm{HAT}=\mathrm{p}(\mathrm{IBD}=2)+0.5^{*} \mathrm{p}(\mathrm{IBD}=1)\right]$.

\section{Comparison of CNV and visualization on chromosomal level}

For CNV detection the Illumina BAM files, and the CG REF coverage files were screened by the RCP pipeline (Glusman et al. 2015), which compares a given BAM file or CG coverage profile against Reference Coverage Profiles (RCPs) taken from a large set of whole-genome sequences produced either on the Illumina or CG platforms. RCP performs coverage binning with a bin size of $1000 \mathrm{bp}$, GC correction, normalization using reference coverage profiles and merging into larger segments. Thereby it detects and reports changes in ploidy of the classified fragments. Resulting CNVs were visualized on the chromosomal level using the open source visualization tool (http://db.systemsbiology.net/cgi-pub/ genomeMapBlocks.pl).

To identify candidate genes that differ in copy number in their coding regions between the two SP, DGV (Database of Genomic Variants, MacDonald et al. 2014) was used to filter out CNVs ( $\geq 50 \%$ overlap) that are common in the general population. The CNV not annotated in DGV, but occurring in the ATCC or UKN genome were retrieved here.

\section{Comparison of SNVs, small indels and block substitutions across genomes}

To exclude variants arising from technological differences, the data were re-analyzed using an already published filtering strategy (Reumers et al. 2012) allowing better comparison between the two platforms. This reduced the total number of SNV per genome and increased the overall concordance between the two platforms. Post filtering, we subtracted variants present in either one of the above-mentioned platforms and obtained rare events. We filtered this reduced number of variants detected against variants found in one of the following databases: dbSNP 138, 1000 Genome Project, Exome Sequencing Project 6500 and ExAC (Exome Aggregation Consortium). Variants found in one of those databases were considered common or known variants and only the variants, which were not present in any database (called "somatic"), were considered further. To detect differences of potential phenotypic impact, the somatic events were screened for variants potentially affecting splicing and amino acid sequence using the ANNOVAR annotations from RefSeq and Ensembl. The genes annotated to this amino acid changing mutations were sorted for specific occurrence in the "ATCC" or "UKN" genome.

\section{Pathway over-representation analysis}

For overrepresentation analysis, a list of all genes with somatic variants (CNV, SV and SNV) specific for any of the two LUHMES SP was assembled. Using the Ingenuity Pathway Analysis (IPA ${ }^{\circledR}$ ) software (Kramer et al. 2014), it was examined whether there were pathways in which these genes were overrepresented. The output was sorted according to the $p$ value of the over-representation test.

\section{STR phenotyping}

Identity of the used SP was confirmed by STR (Short Tandem Repeat) analysis as described previously (Pallocca et al. 2017). Briefly, DNA samples from the SPs were prepared using a commercial kit (Puregene Cell Kit, Qiagen). The kit GlobalFiler ${ }^{\circledR}$ PCR Amplification Kit (Thermofisher) was then used to determine the cell-specific profile for 16 different genomic loci using an Applied Biosystems GeneMapper 
Device. STR results showed $100 \%$ identity of the profiles of both SP.

\section{Statistics, data mining and data availability}

Cytotoxicity data (ATP, GSH, LDH, resazurin) and qPCR are presented as means of at least three independent experiments, and statistical differences were tested by Student's t-test or ANOVA with post-hoc tests as appropriate, using GraphPad Prism 5.0 (Graphpad Software, La Jolla, USA). The genomic data of the ATCC CRL-2927 cell line have been deposited in the BioProject database as PRJNA38682. Annotated variant files for CNV, SV and SNV (VCF format) for both SP have been deposited for public access at ELIXIR Luxembourg under (https://doi.org/10.17881/LCSB.20180 321.01).

\section{Results}

\section{Similarities and differences in the response to toxicants}

The two subpopulations (SP) of LUHMES cells, "UKN" and "ATCC" were used for comparative neurotoxicity experiments. As reported earlier, the established Parkinsonian model toxicant $\mathrm{MPP}^{+}$(Schildknecht et al. 2017), at a concentration of $5 \mu \mathrm{M}$, triggered cell death in "UKN" but no sign of degeneration in "ATCC" for up to $72 \mathrm{~h}$ (Fig. 1a). This was confirmed in an alternative setup, in which "UKN" LUHMES died after $48 \mathrm{~h}$, when exposed to $\geq 5 \mu \mathrm{M} \mathrm{MPP}^{+}$ while the "ATCC" SP tolerated up to $100 \mu \mathrm{M}$ (Fig. 1b). In line with the observed difference in cell death, "ATCC" LUHMES maintained their pool of the intracellular redoxbuffer glutathione for $72 \mathrm{~h}$, when exposed to $\mathrm{MPP}^{+}$, while this was severely depleted in "UKN" (Fig. 1c). Essentially similar observations were made for ATP (Fig. 1d), an energy metabolite particularly sensitive to $\mathrm{MPP}^{+}$toxicity.

\section{Comparison of the genome structures of the two LUHMES SP}

Having observed these differences, we tested whether the "UKN" and "ATCC" SP were indeed based on the same cell line. Their STR-profiles were compared, and we found $100 \%$ conformity of "UKN" and "ATCC"(Fig. S1). Moreover, this profile agreed with the one provided by ATCC (Fig. S1).

To obtain broader information on the genome status of the cells, whole-genome sequencing (WGS) was performed. Reads were aligned against the human reference genome at a mean coverage of $33.3 \times(98.7 \%$ of the genome was covered with more than $20 \times$ reads) for "UKN", and of $38.9 \times(93.1 \%$ of the genome was covered with $>20 \times$ ) for "ATCC" (Tab. S3).

The first use we made of the WGS data was to establish the kinship-level of the two SP. Using software originally developed for paternity testing [PLINK, (Purcell et al. 2007)] or profiling of tumor heterogeneity, the two genomes were mapped for their "identity by descent" (IBD) and the corresponding PI_HAT score was calculated. The result of 0.9959 is in the range usually found for monozygotic twins or for duplicate tissue samples (Yang et al. 2011). This solidly confirmed the common ancestry of the two SP, and indicated that there was no contamination.

In a next step, the genome data for both cell lines was searched for larger structural rearrangements and copy number changes. Overall chromosomal structure and ploidy were normal for both SP (Fig. 2a). In total, 221 structural variants (SV; typically between $1 \mathrm{kbp}$ and $3 \mathrm{Mbp}$ ) not reported in the common genome databases were identified (Fig S2A). Out of these, $15 \mathrm{SV}$ were present in both SP, three were identified only for the "UKN" SP, and the others (containing 179 inversions) were detected only in the "ATCC" LUHMES (Fig. S2A).

We then identified all genes in the proximity of SV (Fig. S2B). This list of candidate factors for altered toxicant sensitivity were examined for reported functions, and none of them offered a simple explanation for the difference of the two LUHMES SP. We, therefore, analyzed in a next step the copy number variations (CNV) as potential candidates. A sizeable number $(n=297)$ of non-common CNV was identified, some of them SP specific (Fig. 2a). After filtering for overlap with protein-coding regions, $16 \mathrm{CNV}$ were found only in "UKN" cells and 35 only in "ATCC" cells (Fig. S3). As expected, both SP shared some $(n=19) \mathrm{CNV}$, as they originate from the same ancestor. Illustrative examples for the latter group are a $4 \mathrm{kbp}$ deletion on chromosome 9, located within the Muscle Associated Receptor Tyrosine Kinase (MUSK) gene, or a $100 \mathrm{kbp}$ deletion on chromosome 13 located within the G Protein-Coupled Receptor Kinase 1 (GRK1) gene (Fig. 2a; Fig. S 4A+B).

Moreover, both cell lines had the same two transgene insertion sites (Fig. 2a), which were mapped to the intronic regions of the cullin 1 (Cul1) gene on chromosome 7 (Fig. 2b) and an intergenic region of chromosome 15 (Fig. 2c).

\section{Single nucleotide variants (SNV) affecting protein amino acid sequence}

Altogether about 4.5 million SNV (= small mutations) were called, when the LUHMES genomes were compared to the reference genome (Fig. S5A). These were filtered for known and common variants (Fig. S5 A-C), and quality corrected and filtered for technology biases (Reumers et al. 2012). 

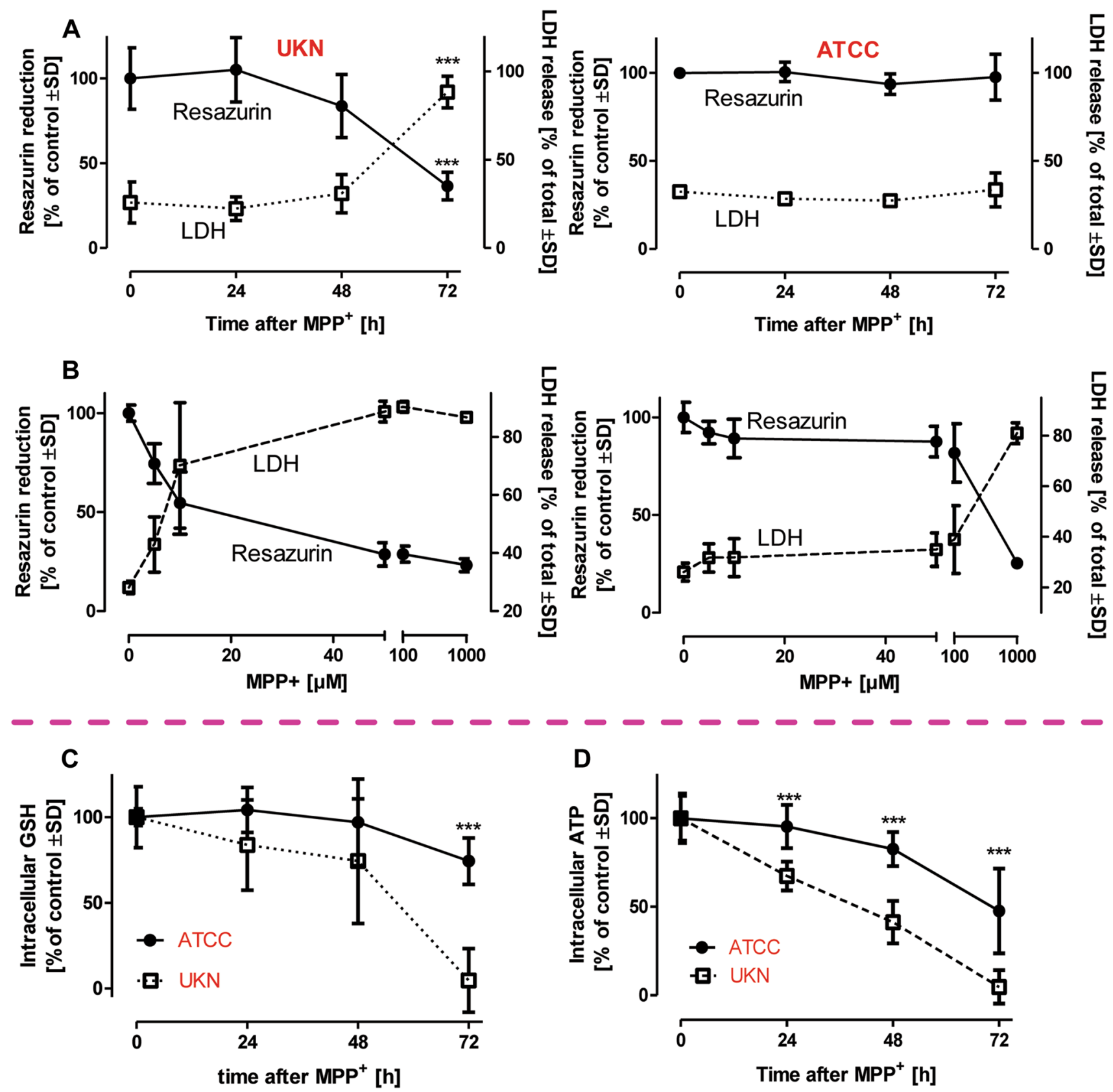

Fig. 1 Similarities and differences in the reaction to different toxicants. LUHMES cells from two different sources [University of Konstanz (UKN); American Type Culture Collection (ATCC)] were cultured according to a standard protocol. LUHMES cells were seeded at a density of $1.5 \times 10^{5}$ cells $/ \mathrm{cm}^{2}$ at $\mathrm{d} 2$. Medium was exchanged at $\mathrm{d} 4$ and exposed to $\mathrm{MPP}^{+}$starting at d6. a Viability was assessed at d9 by measuring resazurin reduction and $\mathrm{LDH}$ release after cells have been exposed to $\mathrm{MPP}^{+}[5 \mu \mathrm{M}]$ for times as indicated. Data are means $\pm \mathrm{SD}$ of three independent experiments. $* * * p \leq 0.001$ b UKN and ATCC

This resulted in 23,400 LUHMES specific SNV (not occurring in the general population) in LUHMES genomes (Fig. S5B). Further selection for changes predicted to change an amino acid in proteins (Fig. S5C) resulted in a final set of

D

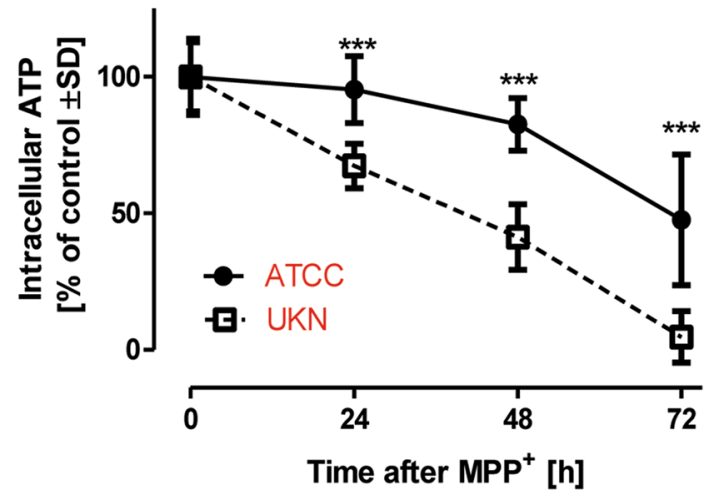

LUHMES were incubated with indicated concentrations of $\mathrm{MPP}^{+}$. After $48 \mathrm{~h}$ viability was assessed measuring resazurin reduction and $\mathrm{LDH}$ release, Data are means $\pm \mathrm{SD}$ of three independent experiments. c Intracellular levels of total glutathione (GSH + GSSG) were measured in cells treated with $\mathrm{MPP}^{+}[5 \mu \mathrm{M}]$ for indicated time periods and represent means \pm SD of three independent experiments. d Intracellular levels of total ATP were measured in cells treated with $\mathrm{MPP}^{+}[5$ $\mu \mathrm{M}]$ for indicated time periods. Data are means \pm SD of three independent experiments. $* * * p \leq 0.001$

29 protein changing variants (Fig. 3a) that differed between "UKN" and "ATCC" LUHMES, and 33 rare variants found in both LUHMES SP (Fig. S5C). 


\section{A \\ Chromosome number:}

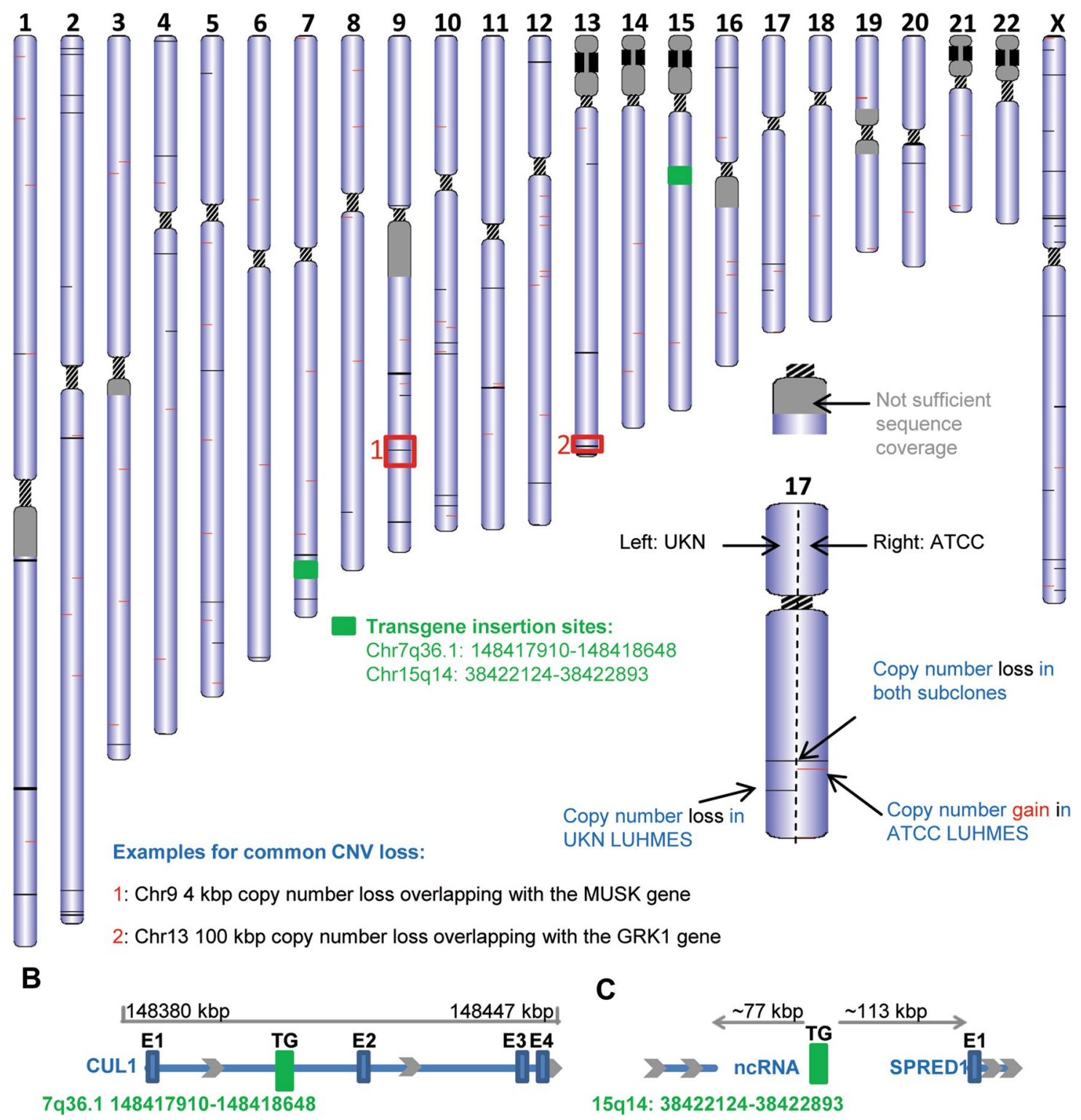

Fig. 2 Genome-wide copy number status. LUHMES cells from two different sources [University of Konstanz (UKN); American Type Culture Collection (ATCC)] were sequenced by either complete genomics (UKN) or Illumina (ATCC) sequencing platforms. a Copy number variations and transgene insertion sites were depicted on chromosome level. CNVs were visualized on the chromosomal level using the open source visualization tool (http://db.systemsbio logy.net/cgi-pub/genomeMapBlocks.pl). Black lines indicate losses

From the group of differential mutations, we selected candidates (Fig. 3a, marked in red) that might be responsible for toxicological differences observed between the SP (based on their known biological role). Western blotting was used to investigate altered expression levels of NRXN3 (neural cell adhesion molecule), HSF1 (master controller of the heat shock response), and SIRT6 (cell stress and and red lines gain in CNV. Transgene insertion sites are marked in green. Examples chosen for detailed resolution are indicated with red boxes and labeled 1 and 2. Detailed resolutions are depicted in Fig. S4. b Graphical scheme of transgene insertion site on chromosome 7 , which is located within an intron of the Cullin 1 gene. Coordinates are based on the GRCh27 reference genome. c Graphical scheme of transgene insertion site on chromosome 15 , which is located in the intergenic region

progeria-associated protein deacetylase). For these three candidate genes, we observed indeed different protein levels in neuronally differentiated LUHMES (Fig. 3b-f). NRXN3 is known for extensive alternative splicing (Rowen et al. 2002), and the ratio of its major bands differed strongly in "ATCC" vs. "UKN" neurons (Fig. 3b, c). SIRT6, although expressed normally in proliferating LUHMES (d0), was 


\begin{tabular}{|l|l|l|l|}
\hline A & \multicolumn{2}{ll}{ Predicted amino acid changing SNVs } \\
Both platforms & UKN only & ATCC only \\
BTBD16 & MECOM & FAM71D & A4GALT \\
C6orf223 & MESP1 & NOTCH3 & B3GNT3 \\
COBLL1 & MLIP & NRXN3 & C6orf132 \\
COL6A5 & MTTP & OTOF & CACNA1G \\
CRACR2A & PCYOX1L & PCCA & DAB2IP \\
CRIP3 & PLA2G6 & SOX13 & FAM166B \\
CTNS & PLEK2 & URB1 & FBXL16 \\
DMGDH & PRDM6 & & FHOD3 \\
DPYD & PTHLH & & GJC2 \\
FAM216B & PTK7 & & HSF1 \\
IGFN1 & RPA1 & & SIRT6 \\
KCP & SMG6 & & \\
KRTAP19-5 & TMEM140 & & \\
LOXL2 & TMEM173 & & \\
LRRC69 & UCP1 & & \\
LZTS3 & USP38 & & \\
MCTP1 & & & \\
\hline
\end{tabular}

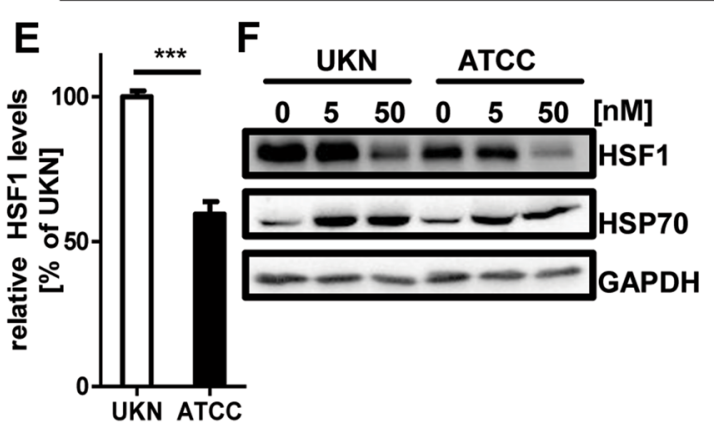

Fig. 3 Amino acid changing SNVs. SNVs affecting proteins in LUHMES from two different sources [University of Konstanz (UKN); American Type Culture Collection (ATCC)] were filtered from the total SNVs called as described in the material and methods section in detail. a Genes affected by common LUHMES SP and "UKN" or "ATCC" specific amino acid changing SNV. The genes marked in red were further assessed on protein level for differences between the two SP. b Undifferentiated (d0) and mature (d6) LUHMES cells were lysed and analysed by Western blot analysis using anti- NRXN3, anti-SIRT6 and anti-GAPDH antibodies. c, d Densitometric quantification of band intensities of NRXN3 in d6 cells (c) and SIRT6 in d6 cells (d). e Densitometric quantification of

strongly down-regulated in d6 "ATCC", compared to d6 "UKN" (Fig. 3b, d). Moreover, HSF1 was found at lower levels in "ATCC" compared to "UKN" (Fig. 3e, f). To test for functional implications of this finding, cells were exposed to the HSP90 inhibitor geldanamycin. As expected, HSF-1 was down-regulated in both SP. At the same time, a counterregulation of HSP70 was observed in both SP (Fig. 3f, g). This suggests that the mutation in HSF1 ("ATCC") did not abolish the overall function of this transcription factor, but it

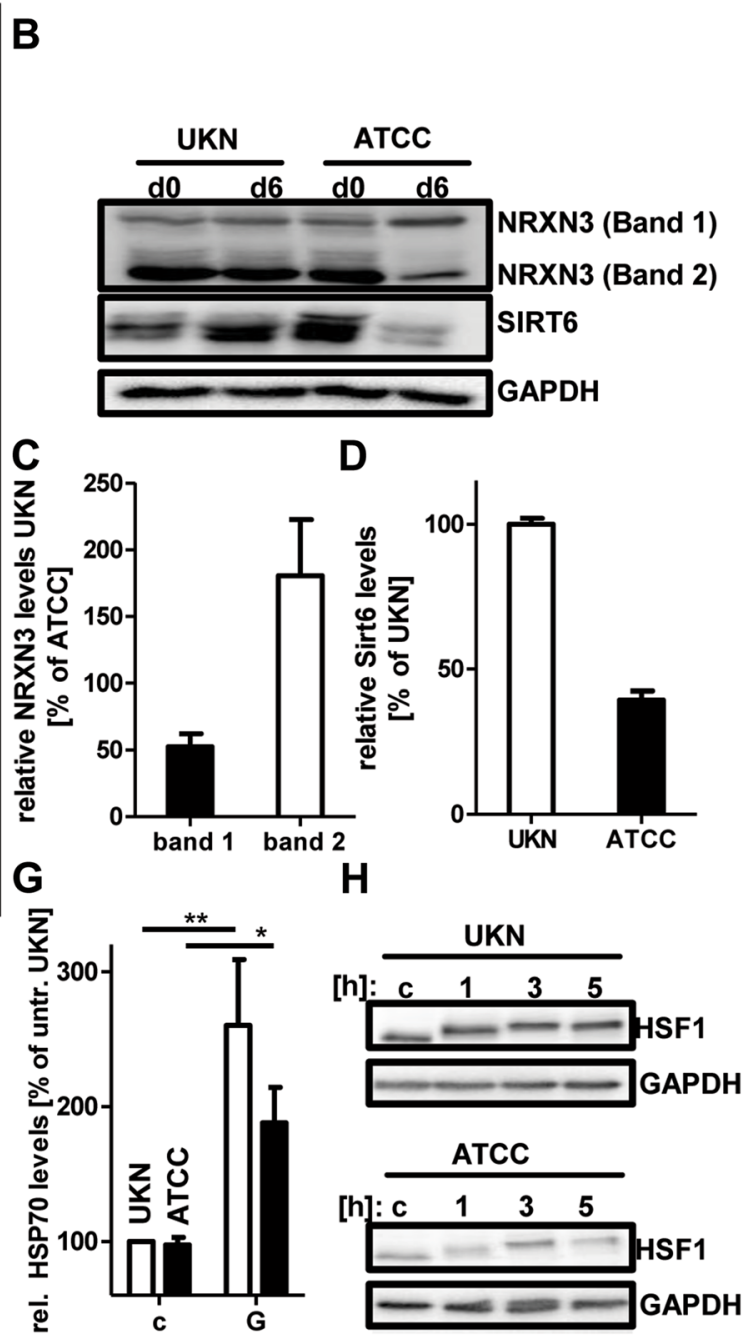

band intensities of HSF1 in d6 cells. Intensities are depicted relative to the intensity in the "UKN" SP. f LUHMES (d6) cells of both SP were treated with indicated concentrations of Geldanamycin for $24 \mathrm{~h}$. After incubation cells were lysed and analysed by Western blot using anti-HSF1, anti-HSP70 and anti-GAPDH antibodies. g Densitometric quantification of band intensities of HSP70 induction by Geldanamycin. Intensities are depicted relative to the intensity in the untreated "UKN" SP. Band intensities of 5 and $50 \mathrm{nM}$ Geldanamycin were combined. h LUHMES (d6) cells of both SP untreated (c) and with indicated time after start of heat shock $\left(43^{\circ} \mathrm{C} / 1 \mathrm{~h}\right)$. After incubation, cells were lysed and analysed by Western blot using anti-HSF1 and anti-GAPDH antibodies

affected its overall cellular expression levels (Fig. 3e, f). This was also confirmed when cells were exposed to heat stress. As described earlier (Budzynski et al. 2015) this leads to a rapid post-translational modification (higher apparent $\mathrm{MW}$ ) of HSF-1, and this biochemical feature was observed in both SP (Fig. 3h). These findings provide proof of principle that genetic differences between the LUHMES SP, identified by WGS, lead to biochemically measurable alterations. Some of the identified genes are involved in controlling cellular 

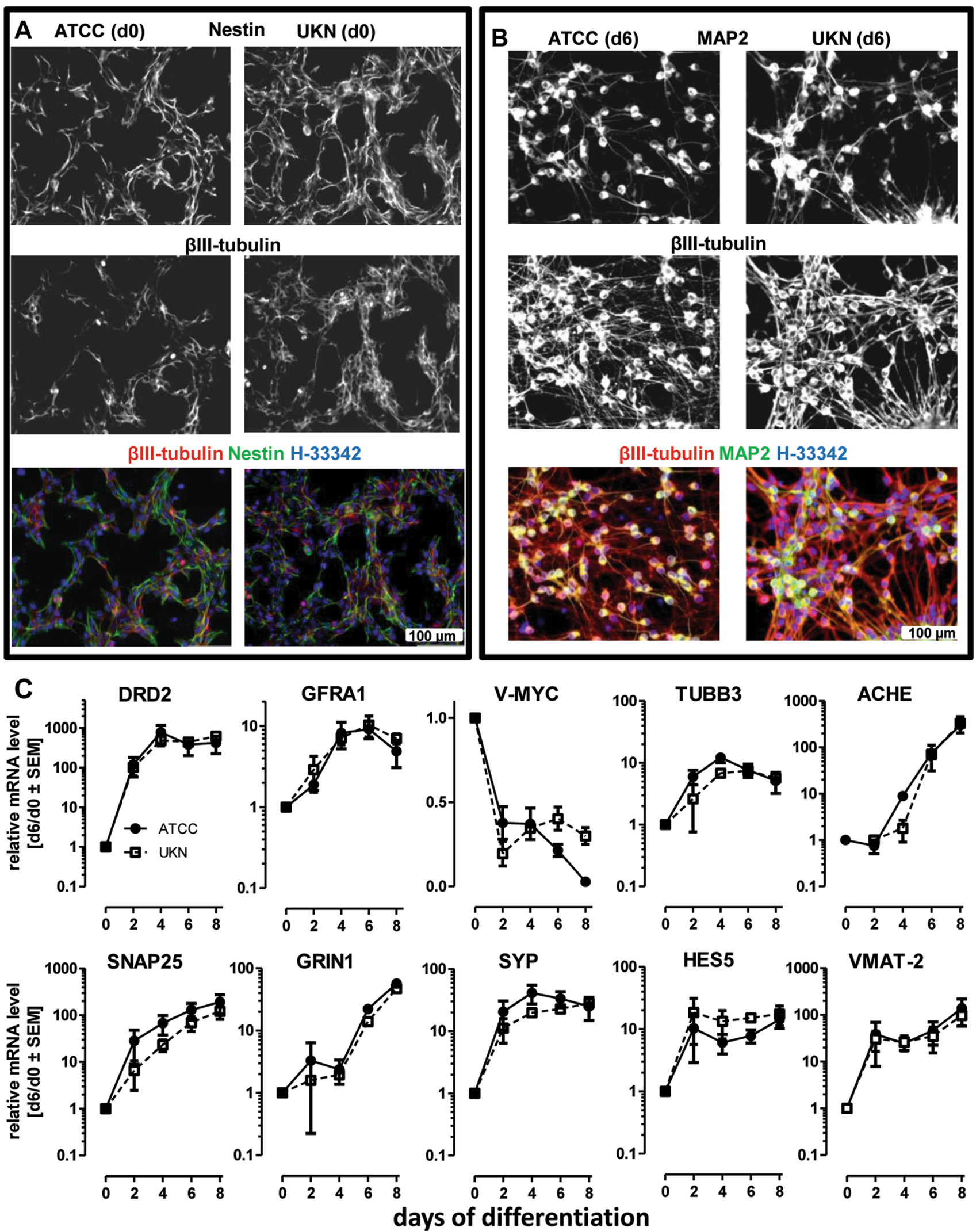

days of differentiation 
४Fig. 4 Similarities in neuronal differentiation. LUHMES cells from two different sources [University of Konstanz (UKN); American Type Culture Collection (ATCC)] were cultured and differentiated according to the published standard protocol. a Morphology and structural properties of undifferentiated LUHMES (d0) cells (of both SP) were assessed by immunocytochemistry staining for $\beta$-III tubulin, Nestin and H-33342. b Morphology and structural properties of differentiated LUHMES (d6) cells (of both SP) seeded at a density of $0.5 \times 10^{5}$ cells $/ \mathrm{cm}^{2}$ were assessed by immunostaining for $\beta$-III tubulin (red), MAP2 (green) and H-33342 (blue). c LUHMES cells were differentiated for the indicated time points $(0 ; 2 ; 4 ; 6 ; 8$ days) and mRNA samples were prepared Changes in gene expression of the neurodevelopmental marker genes DRD2, GFRA1, v-MYC, TUBB3; ACHE, SNAP25, GRIN1, SYP, HES5 and VMAT-2 of LUHMES cells from both SP were monitored by qPCR. Values are expressed relative to expression levels in undifferentiated LUHMES cells. Data are means \pm SEM for three different experiments. (Color figure online)

resilience (e.g. HSF1) or aging/degeneration (SIRT6). To explore the functional implication of many potential candidates with respect to $\mathrm{MPP}^{+}$toxicity in LUHMES appeared to be impossible within a reasonable time span. We performed, therefore, additional toxicity experiments to narrow down the list of genes with matching biological properties. Rotenone has the same cellular target as $\mathrm{MPP}^{+}$(Terron et al. 2018), colchicine is general inducer of neuronal apoptosis (Volbracht et al. 1999), and antimycin A /DETA-NONOate trigger different types of oxidative stress and mitochondrial inhibition. They all showed the same toxicity to "ATCC" and "UKN" LUHMES (Fig. S6). These findings suggest that genes involved in general cell death regulation do not account for the differences observed for $\mathrm{MPP}^{+}$(Fig. 1).

\section{Detailed phenotypic characterization}

The small genetic changes and the resultant biochemical modifications may subtly affect the neuronal differentiation of cells, and therewith their toxicological response to a specific neurotoxicant. Therefore, we undertook a detailed phenotypic characterization. The overall morphology of the two SP was assessed by immunocytochemistry (ICC), and expression of marker genes [evaluated for the initial characterization of "UKN" LUHMES (Scholz et al. 2011)] was quantified by qPCR. Undifferentiated (d0) SP were similar with respect to the patterns of nestin and $\beta$-III-tubulin staining (Fig. 4a), and also differentiated cells (d6) appeared to be morphologically similar, as indicated by the distribution of microtubule-associated protein-2 (MAP2), $\beta$-III-tubulin and post-synaptic density protein 95 (PSD95) (Fig. 4b; Fig. S7). We compared the changes in gene expression for marker genes (Fig. 4c). No differences between the SP were observed for DRD2, GFRA1, TUBB3, SYP, SNAP25, GRIN1, HES5, VMAT-2 and ACHE, and the down-regulation of the v-myc transgene, upon tetracycline addition, was equally effective in both SP (Fig. 4c). Based on these data, the two SP would be rated as being similar.

To unravel more subtle differences, we quantified neurite growth (Fig. 5a) as functional endpoint (Krug et al. 2014; Stiegler et al. 2011). Both SP formed an intricate neurite network, but "ATCC" LUHMES displayed a significantly higher neurite area per cell compared to "UKN" LUHMES at day 3 and 6 of differentiation (Fig. 5b, c). This hints to subtle differences in differentiation control between the two SP, possibly linked to signaling factors or transgene activity.

\section{Differences in the reversal of differentiation}

To scrutinize the efficiency of the tet-off system more thoroughly, an experimental setup was developed that triggered neuronal differentiation for 4 days, and then probed, to which extent it could be reversed by re-addition of FGF and withdrawal of GDNF/tetracycline (Fig. 5d). "Reversal" was measured as a number of cells re-entering the cell cycle (EdU incorporation). A higher percentage of EdU positive (reversal) cells was observed in "UKN" compared to "ATCC" (Fig. 5e). This was confirmed by other cell cycle markers, such as Ki67 and CycA1, and it fully agreed with a stronger re-induction of cell cycle genes in "UKN" compared to "ATCC" LUHMES (Fig. 5e, f; Fig. S8A+B). These experiments hinted to a subtle difference in transgene shutoff and differentiation speed between the two SP. As "ATCC" attained the post-mitotic neuronal phenotype faster than "UKN", the differentiation efficiency does not explain the reduced sensitivity to the neurotoxicant $\mathrm{MPP}^{+}$. However, it may have an impact on other types of experiments LUHMES may be used for.

\section{Differences in the dopaminergic phenotype}

Another explanation of the sensitivity differences may be an effect on an upstream regulatory circuit related to the dopaminergic properties of LUHMES. To probe this hypothesis, we performed over-representation analysis of the identified mutations with respect to known signaling and regulation pathways. Amongst the top five most over-represented pathways, we identified "cAMP signaling", "dopamine receptor signaling" and "tetrahydrobiopterin biosynthesis" in "UKN" LUHMES and "protein kinase A signaling" in "ATCC" LUHMES as potential explanations. These pathways affect the dopaminergic differentiation and the key enzyme $\mathrm{TH}$, and polygenic effects on these regulatory circuits could result in differences in the dopaminergic phenotype (Fig. S9-11).

Considering the results of the pathway enrichment analysis, we wondered whether differences in the dopaminergic phenotype might account for the observed differential toxicity, even though none of the central genes (DAT, TH, 


\section{A}

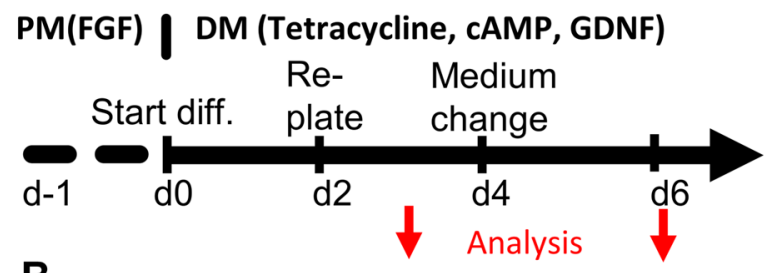

B

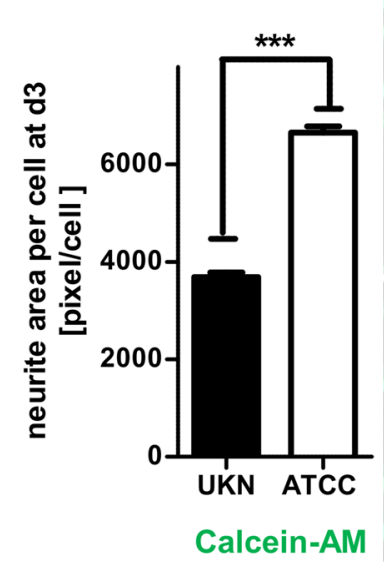

C

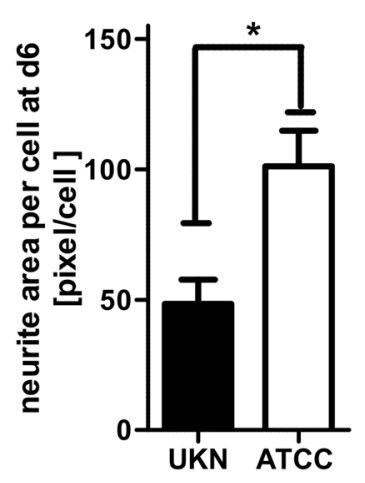

BIII-tubulin
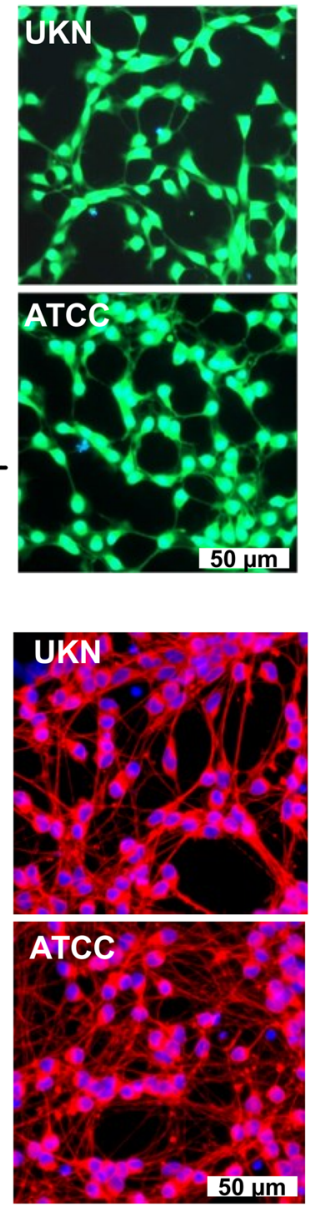

D

Terminal neuronal differentiation:

(1) Differentiation medium (DM)

Reversibility protocol:

(2)

PM

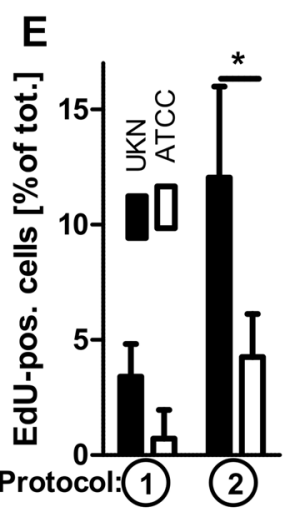

$\mathbf{G}$
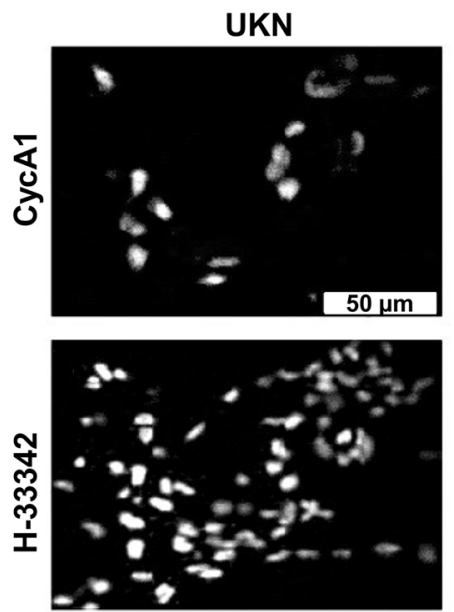

$\mathbf{F}$
PM: Proliferation medium (bFGF)
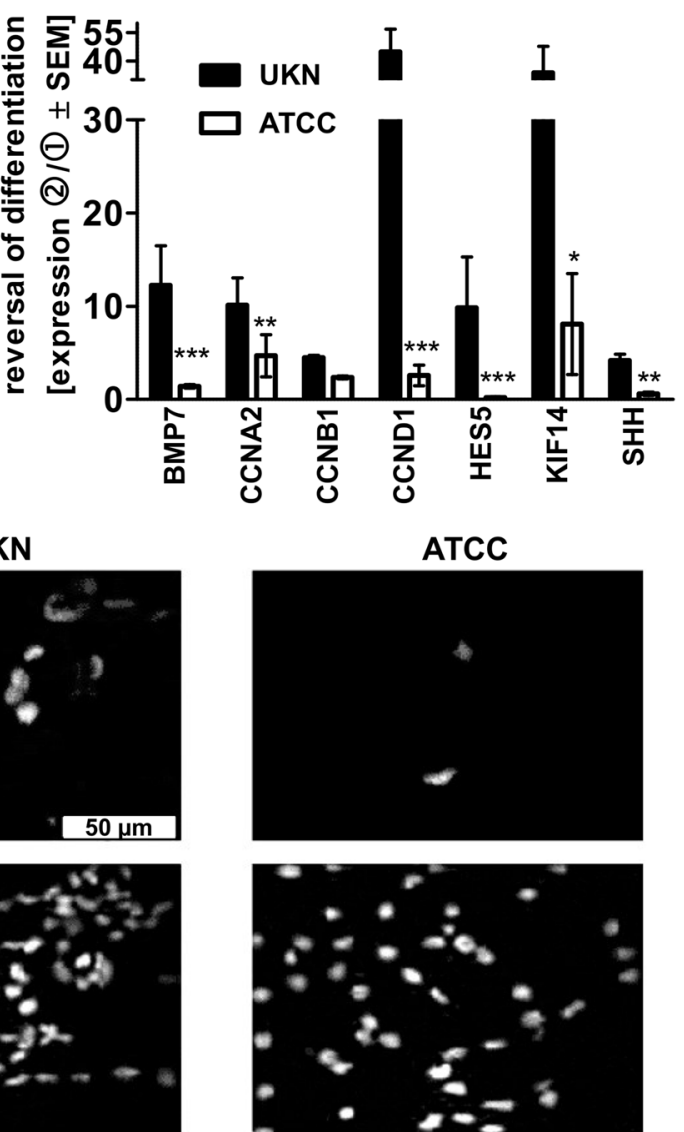

Fig. 5 Comparison of neurite outgrowth and cell cycle exit. LUHMES cells from two different sources [University of Konstanz (UKN); American Type Culture Collection (ATCC)] were differentiated according to a published standard protocol. a Cells were replated at $\mathrm{d}-1$ and differentiation was started by removal of proliferation medium (PM) and the addition of differentiation medium (DM) containing tetracycline, cAMP and GDNF at d0. Cells were re-plated at a density of $1.5 \times 10^{5}$ cells $/ \mathrm{cm}^{2}$ at $\mathrm{d} 2$. Medium was exchanged at $\mathrm{d} 4$ and "mature cells" were ready at d6, e.g. for measurement of the neurite network or toxicant exposure. b Cells of both SP were stained on $\mathrm{d} 3$ with calcein-AM and H-33342. The neurite area per field was assessed in live cultures by automated microscopy in combination with an algorithm adapted for neurite area quantification (cellomics). In parallel, the number of cells per field was quantified (H-33342 positive nuclei), so that the average area/cell could be calculated. c "UKN" and "ATCC" SP were differentiated until d6. These cells were fixed and neurites were assessed by immunocytochemistry staining for $\beta$-III tubulin and H-33342. The total neurite area per field (based on $\beta$-III-tubulin positive pixels) was measured by automated microscopy in combination with an algorithm adapted for neurite area quantification (cellomics). In parallel, the number of cells per field was quantified, so that the average area/cell could be calculated. d LUHMES cells of both SP were cultured in two different cultivation procedures. Therefore medium was exchanged at $\mathrm{d} 4$ to either (1) differentiation medium (DM) or (2) proliferation medium (PM). e Experiment was stopped at d6 and the EdU positive cells for both culture conditions were quantified using fluorescence microscopy and automated counting. $\mathbf{f}$ Changes in gene expression in cell cyclerelated genes of cells treated with proliferation medium (2) relative to cells differentiated according to the standard protocol (1) were measured at d6 and expressed as the ratio of condition (2)/condition (1). $\mathbf{g}$ Cell cycle activity of LUHMES cells of both SP cultured according to 2 was assessed by immunocytochemistry staining for cyclin A1 and H-33342. Data are means \pm SD for three independent cell differentiations of different passages. $* * * p \leq 0.001 * * p \leq 0.01 * p \leq 0.5$ 
VDAC2, AADC, GFRA2, NURR1, LMX1, etc.) appeared to be directly mutated. LUHMES cells have been used as a model for dopaminergic neurons in several studies, and MPP+-toxicity depends on such properties (Delp et al. 2017; Efremova et al. 2015; Lotharius et al. 2005; Zhang et al. 2014). We, therefore, compared the mRNA expression levels of dopaminergic markers during the differentiation. Interestingly, both SP strongly up-regulated the dopamine transporter (DAT) and GDNF receptor (GFRA2) at day 2 of differentiation, but the "ATCC" SP down-regulated these two genes at day 4-8 of differentiation, while they stayed upregulated in the "UKN" LUHMES (Fig. 6a). Furthermore, there were also significant differences in the regulation of tyrosine hydroxylase (TH), the rate determining enzyme of dopamine synthesis, and few other neuro-specific genes (DBH and SYN1) (Fig. 6a). In line with the lower TH levels, there was a difference in the intracellular dopamine levels, which further confirmed a weaker dopaminergic phenotype of the "ATCC" subclone compared to "UKN" (Fig. 6b). Relative expressions at day 8 differed between the two SP for DAT, GFRA2, DBH and TH (Fig.S12A). Accordingly,
TH and DAT protein was abundant in "UKN" LUHMES on d8 but not in the "ATCC" SP (Fig. S12B +C). Moreover, the uptake of $\mathrm{MPP}^{+}$a substrate of the dopamine transporter was significantly higher in "UKN" compared to "ATCC" LUHMES (Fig. 6c). Use of the specific DAT-blocker GBR129009 confirmed that all $\mathrm{MPP}^{+}$uptake was mediated by the DAT and that this functional difference would impact $\mathrm{MPP}^{+}$toxicity (Fig. 6d).

\section{Discussion}

LUHMES cells are used as highly reproducible test system for neurotoxicity investigations or to model aspects of neurodegenerative disease (Delp et al. 2017, 2018; Harris et al. 2017; Krug et al. 2014; Poltl et al. 2012; Sarkar et al. 2017; Schildknecht et al. 2013; Scholz et al. 2011; Stiegler et al. 2011; Szego et al. 2017; Xiang et al. 2013; Zhang et al. 2014). Since the $\mathrm{MPP}^{+}$model for Parkinson's disease is frequently used by us and others (Schildknecht et al. 2017; Terron et al. 2018), the finding that the induction of cell death in LUHMES
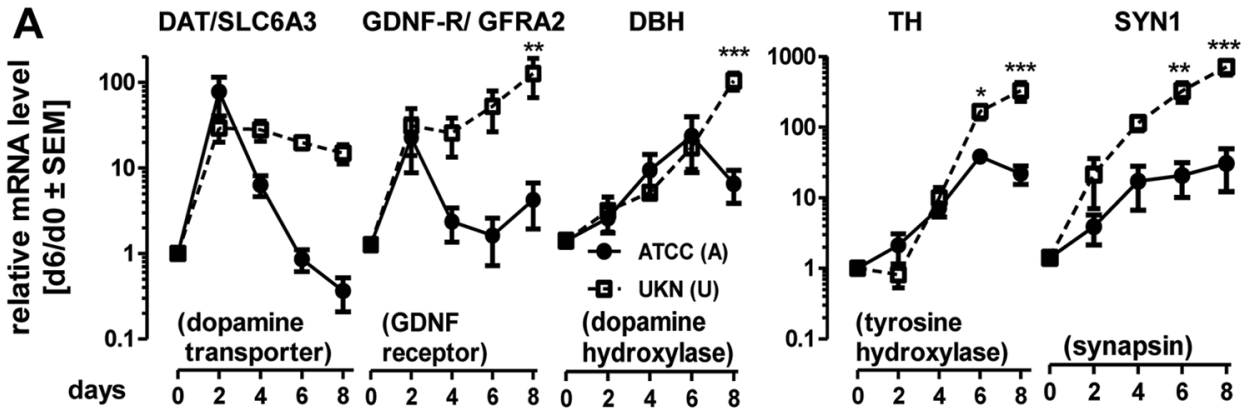

B

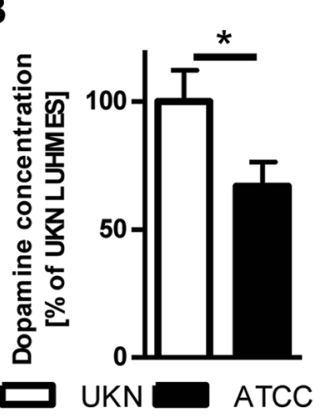

C

D
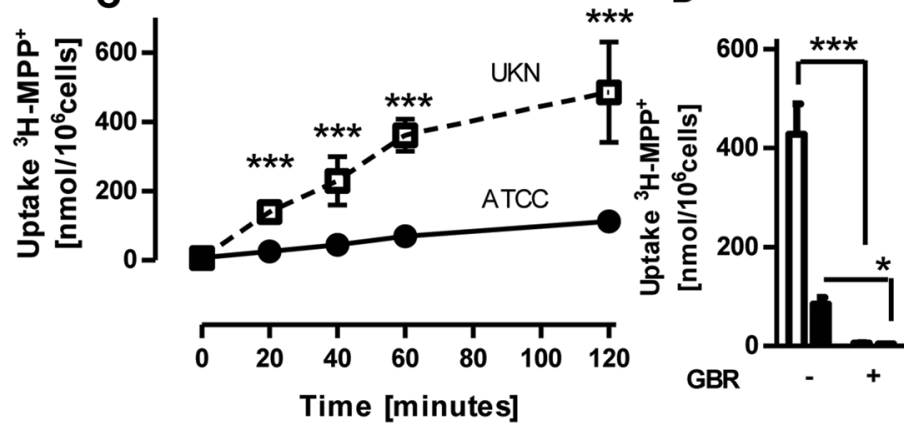

Fig. 6 Significantly changed differentiation markers. LUHMES cells from two different sources [University of Konstanz (UKN); American Type Culture Collection (ATCC)] were cultured according to a standard protocol. a LUHMES cells were differentiated for the indicated time points $(0 ; 2 ; 4 ; 6 ; 8$ days $)$ and mRNA samples were prepared. Changes in gene expression of the neurodevelopmental marker genes DAT, GFRA2, DBH, TH and SYN1 were monitored for both SP. Values are expressed relative to expression levels in undifferentiated LUHMES cells and represent means \pm SEM from three independent experiments. $* * * p<0.001 * * p<0.01 * p<0.5$. b Dopamine content of LUHMES (d6) cells of both SP was analyzed using a Dopamine
ELISA Kit (Abnova). c Uptake of ${ }^{3} \mathrm{H}-\mathrm{MPP}^{+}$in "UKN" and "ATCC" SP was assessed for incubation times as indicated. Therefore, $5 \mu \mathrm{M}$ $\mathrm{MPP}^{+}$containing $0.3125 \mu \mathrm{Ci}{ }^{3} \mathrm{H}-\mathrm{MPP}^{+}$were applied to the cultures and radioactivity in supernatant and cell lysates was measured using a scintillation counter. Data are means $\pm \mathrm{SD}$ from three independent experiments $* * * p<0.001$. d Uptake of ${ }^{3} \mathrm{H}-\mathrm{MPP}^{+}$in "UKN" and "ATCC" LUHMES was measured after $2 \mathrm{~h}$ incubation. Therefore, $5 \mu \mathrm{M} \mathrm{MPP}{ }^{+}$containing $0.3125 \mu \mathrm{Ci}^{3} \mathrm{H}_{-} \mathrm{MPP}^{+}$in presence or absence of GBR-12909 [1 $\mu \mathrm{M}$ ] were applied to the cultures. Radioactivity in supernatant and cell lysates was measured using a scintillation counter. $* * * p<0.001$ 
purchased from ATCC required 16 times higher concentration of the neurotoxicant $\mathrm{MPP}^{+}$(Zhang et al. 2014), than found for the original cells ("UKN") (Krug et al. 2014; Poltl et al. 2012; Schildknecht et al. 2009), raised concerns about the definitions of cell line identity. Even though we found here SP of LUHMES from different sources to be highly similar on the genomic level (same STR-profile; PI_HAT score $\approx 1$ ), we identified clear phenotypic and toxicological differences using a targeted identity profiling. The attenuated dopaminergic phenotype identified in the "ATCC" SP, explained the selectively increased resistance to the Parkinsonian toxicant $\mathrm{MPP}^{+}$. The results of this study thus provide compelling evidence that standard measures of cell definition, ranging from phenotypic markers, over STR profiling and even WGS data are not sufficient to define cell identity. Even highly related cell populations have too many differences to be followed up, especially if it is considered that also non-coding variants may play important roles. From disease biology it is well-known that mild (no full loss of any gene) copy number variation can have pronounced effects, and the gene combinations responsible for such effects have been hard to define (Nielsen et al. 2017). Our findings, together with these background considerations, suggest that targeted testing, related to the specific functional demands of cells in a given study, is required.

Here, we successfully showed that the two LUHMES SP are indeed derived from the same cells. Although, this may appear trivial, it is an important confirmation, as a lot of commonly used cell lines are misidentified (e.g. wrong tissue origin or wrong species) or contaminated by other cells (e.g. HeLa)(Dirks and Drexler 2013; Dolgin 2016; Gartler 1968; Hughes et al. 2007; Landry et al. 2013; Pamies et al. 2017; Reid 2017). During the last decades, as cross-contaminations and cellular misidentifications became apparent, the importance of cell line identity gained increasing attention (Dirks and Drexler 2013; Freedman 2015; Freedman et al. 2015b). The rapid development in the field of genome sequencing allowed us now to address questions on genetic drift and stability at higher levels of resolution.

Since we observed very high genetic concordance and two identical transgene insertion sites in each SP, our WGS data confirmed the common clonal origin of the two SP. Nevertheless, we also detected differences on the genome level, which initially appeared to be relatively high in number. This may be in part be due to two different sequencing platforms used here to derive WGS data and the resulting slight differences in genome coverage and calling algorithms. However, after application of established software tools and quality assurance, to correct for the noise generated by the different sequencing platforms (Reumers et al. 2012), the number reduced drastically and was in the range of other reports (Cheng et al. 2012; Gore et al. 2011).

One remaining non-corrected difference is the overrepresentation of inversions in "ATCC". This comes mainly from the different SV calling method used for the Illumina sequencing data. SVs were here called with a newly developed method called Manta (Chen et al. 2016) that is not available for Complete Genomics data. Therefore, it is not clear, if those inversions are SP specific or even false positive calls. The difference had, however, no influence on eh outcome of this study and on the conclusions drawn.

In other studies, genome profiling has been used mainly to describe cellular differences, but even the most recent largescale approaches (Grobner et al. 2018; Ma et al. 2018) fail to make predictions from genome changes to cell function (e.g. altered function or subtype of neoplastic disease). This is, however, circumstantial evidence, that long-term culturing, genetic drift and altered functional properties of cells are causally related. It has been shown that sub-culturing with too many passages may affect cell line characteristics and thereby reproducibility. For example, Caco 2 cells display different transport and toxicological properties with increasing number of passages (Hughes et al. 2007). Genetic heterogeneity of the parental line and sub-selection during culturing is suspected to be the underlying mechanism leading to genetic drift that might result in genetically different cell lines (Baker et al. 2016; Cai et al. 2014; Martins-Taylor and Xu 2012). When cell lines are used for protein production, stringent single cell cloning has been suggested as a favorable way to ensure cell identity and production quality. However, this was recently doubted as a study showed that also single-cellclone-derived cell populations comprise variants of production efficiency and quality, up to the level of changes in copy number of transgene within the population (Ko et al. 2017).

Even though we confirmed some of the amino acid changing events (e.g. HSF1) that distinguished the LUHMES SP, none of those conclusively explained the observed differences in the toxicological response. The similar sensitivity to largely diverse toxicants suggests that fundamental apoptosis and stress pathways did not differ between the SP.

Bioinformatic data-mining revealed that genetic alterations are particularly frequent within pathways related to the dopaminergic phenotype. Intracellular dopamine has been clearly identified as factor promoting neuronal cell death (Mor et al. 2017; Mosharov et al. 2009). Therefore, the capacity of LUHMES to produce dopamine results in a selective pressure to accumulate mutations affecting their dopaminergic phenotype. Both SP seemed to have taken a different path to decrease potential dopamine toxicity. For "ATCC", the down-regulation of tyrosine-hydroxylase (TH) is the most obviously reducing dopamine stress. Interestingly, this did not occur by inactivation of the $\mathrm{TH}$ gene, but rather by some upstream regulation. In the same vein, dopamine transporter (DAT) was affected indirectly, and in a way that was not obviously predicted by genome data.

Direct phenotypic characterization helped to identify differences in the dopaminergic phenotype of the SP. 
Especially, the lower expression and activity levels of the DAT provides a conclusive and sufficient explanation for the observed differences in the toxicological response to $\mathrm{MPP}^{+}$, as the toxicant requires this transporter (Schildknecht et al. 2015, 2017; Terron et al. 2018) to enter the cells. The toxicity we observed at higher concentrations of $\mathrm{MPP}^{+}$ $(\geq 100 \mu \mathrm{M})$ in the "ATCC" SP might be mediated by low abundance of the DAT (down-regulated, but not totally deficient) or by other transporters, such as the organic cation transporter-3 (Cui et al. 2009; Schildknecht et al. 2015, 2017). The fact that both SP reacted similarly to rotenone, a toxicant with the same target as $\mathrm{MPP}^{+}$(mitochondrial complex I), suggests that toxicokinetic (i.e. transport) factors were mainly responsible for the observed sensitivity difference with $\mathrm{MPP}^{+}$

In summary, the data presented here provide an important example for gaps in the commonly used cell identification approaches, and for the need to reconsider good practices in the field (Leist et al. 2014; Pamies et al. 2017; Ramirez et al. 2013; Reid 2017; Stacey 2012, 2017). To ensure proper cell functionality, we suggest to include a "fit-for-purpose" phenotypic testing strategy in cell authentication procedures, and to define performance standards for desired cell functions. Examples for such a testing strategy could be (1) to include testing for dopamine transporter expression and functionality via measurement of $\mathrm{MPP}^{+}$uptake when establishing the $\mathrm{MPP}^{+}$model or (2) measurement of $\mathrm{A} \beta$ secretion when using the cells to model processing of the amyloid precursor protein (APP) (Scholz et al. 2018). Adoption of such standards would improve reproducibility of in vitro data and comparability across studies. Therefore, an important issue concerning a perceived reproducibility crisis of science (Freedman 2015; Freedman et al. 2015a, b) would be addressed. Future refinements can be envisaged already now, e.g. addressing heterogeneity and genetic mosaicism within given SP, for example by single cell sequencing (McConnell et al. 2013) or functional testing after subcloning.

Acknowledgements P.M. received support from the Luxembourg government through the "plan Technologies de la Santé" and the National Centre of Excellence in Research on Parkinson's disease (NCER-PD) grant from the FNR. Bioinformatics analyses presented in this paper were carried out in part using the HPC facilities of the University of Luxembourg (see http://hpc.uni.lu). The work was facilitated by grants from the Land Baden Württemberg, EU-ToxRisk and the German Federal Ministry of Education and Research (BMBF).

\section{Compliance with ethical standards}

Conflict of interest The authors declare that they have no conflict of interest.

Data availability statement The genomic data of the ATCC CRL2927 cell line have been deposited in the BioProject database as PRJNA38682. Annotated variant files for CNV, SV and SNV (VCF format) for both SP have been deposited for public access at ELIXIR Luxembourg under (https://doi.org/10.17881/LCSB.20180321.01).

Open Access This article is distributed under the terms of the Creative Commons Attribution 4.0 International License (http://creativeco mmons.org/licenses/by/4.0/), which permits unrestricted use, distribution, and reproduction in any medium, provided you give appropriate credit to the original author(s) and the source, provide a link to the Creative Commons license, and indicate if changes were made.

\section{References}

Baker D, Hirst AJ, Gokhale PJ et al (2016) Detecting genetic mosaicism in cultures of human pluripotent stem cells. Stem Cell reports 7(5):998-1012. https://doi.org/10.1016/j.stemcr.2016.10.003

Balmer NV, Weng MK, Zimmer B et al (2012) Epigenetic changes and disturbed neural development in a human embryonic stem cellbased model relating to the fetal valproate syndrome. Hum Mol Genet 21(18):4104-4114. https://doi.org/10.1093/hmg/dds239

Bian X, Yang Z, Feng H, Sun H, Liu Y (2017) A Combination of species identification and STR profiling identifies cross-contaminated cells from 482 human tumor cell lines. Sci Rep 7(1):9774. https:// doi.org/10.1038/s41598-017-09660-w

Budzynski MA, Puustinen MC, Joutsen J, Sistonen L (2015) Uncoupling stress-inducible phosphorylation of heat shock factor 1 from its activation. Mol Cell Biol 35(14):2530-2540. https://doi. org/10.1128/MCB.00816-14

Cai J, Miao X, Li Y et al (2014) Whole-genome sequencing identifies genetic variances in culture-expanded human mesenchymal stem cells. Stem Cell Rep 3(2):227-233. https://doi.org/10.1016/j. stemcr.2014.05.019

Cai X, Evrony GD, Lehmann HS et al (2015) Single-cell, genome-wide sequencing identifies clonal somatic copy-number variation in the human brain. Cell Rep 10(4):645. https://doi.org/10.1016/j.celre p.2015.01.028

Chen X, Schulz-Trieglaff O, Shaw R et al (2016) Manta: rapid detection of structural variants and indels for germline and cancer sequencing applications. Bioinformatics 32(8):1220-1222. https://doi. org/10.1093/bioinformatics/btv710

Cheng L, Hansen NF, Zhao L et al (2012) Low incidence of DNA sequence variation in human induced pluripotent stem cells generated by nonintegrating plasmid expression. Cell Stem Cell 10(3):337-344. https://doi.org/10.1016/j.stem.2012.01.005

Coufal NG, Garcia-Perez JL, Peng GE et al (2009) L1 retrotransposition in human neural progenitor cells. Nature 460(7259):11271131. https://doi.org/10.1038/nature08248

Cui M, Aras R, Christian WV et al (2009) The organic cation transporter-3 is a pivotal modulator of neurodegeneration in the nigrostriatal dopaminergic pathway. Proc Natl Acad Sci USA 106(19):8043-8048. https://doi.org/10.1073/pnas.0900358106

Delp J, Gutbier S, Cerff M et al (2017) Stage-specific metabolic features of differentiating neurons: implications for toxicant sensitivity. Toxicol Appl Pharmacol. https://doi.org/10.1016/j. taap.2017.12.013

Delp J, Gutbier S, Klima S et al (2018) A high-throughput approach to identify specific neurotoxicants/developmental toxicants in human neuronal cell function assays. Altex. https://doi.org/10.14573/altex .1712182

Dirks WG, Drexler HG (2013) STR DNA typing of human cell lines: detection of intra- and interspecies cross-contamination. Methods Mol Biol 946:27-38. https://doi.org/10.1007/978-1-62703 $-128-8 \_3$ 
Dolgin E (2016) Venerable brain-cancer cell line faces identity crisis. Nature 537(7619):149-150. https://doi.org/10.1038/natur e. 2016.20515

Drmanac R, Sparks AB, Callow MJ et al (2010) Human genome sequencing using unchained base reads on self-assembling DNA nanoarrays. Science 327(5961):78-81. https://doi.org/10.1126/ science. 1181498

Efremova L, Schildknecht S, Adam M et al (2015) Prevention of the degeneration of human dopaminergic neurons in an astrocyte coculture system allowing endogenous drug metabolism. Br J Pharmacol 172(16):4119-4132. https://doi.org/10.1111/bph.13193

Frattini A, Fabbri M, Valli R et al (2015) High variability of genomic instability and gene expression profiling in different HeLa clones. Sci Rep 5:15377. https://doi.org/10.1038/srep15377

Freedman LP (2015) Know thy cells: improving biomedical research reproducibility. Sci Transl Med 7(294):294ed7. https://doi. org/10.1126/scitranslmed.aac7112

Freedman LP, Cockburn IM, Simcoe TS (2015a) The economics of reproducibility in preclinical research. PLoS Biol 13(6):e1002165. https://doi.org/10.1371/journal.pbio.1002165

Freedman LP, Gibson MC, Ethier SP, Soule HR, Neve RM, Reid YA (2015b) Reproducibility: changing the policies and culture of cell line authentication. Nat Methods 12(6):493-497. https://doi. org/10.1038/nmeth.3403

Gartler SM (1968) Apparent Hela cell contamination of human heteroploid cell lines. Nature 217(5130):750-751

Gerhardt E, Kugler S, Leist M et al (2001) Cascade of caspase activation in potassium-deprived cerebellar granule neurons: targets for treatment with peptide and protein inhibitors of apoptosis. Mol Cell Neurosci 17(4):717-731. https://doi.org/10.1006/ mone.2001.0962

Glusman G, Severson A, Dhankani V et al (2015) Identification of copy number variants in whole-genome data using reference coverage profiles. Front Genet 6:45. https://doi.org/10.3389/fgene .2015 .00045

Gore A, Li Z, Fung HL et al (2011) Somatic coding mutations in human induced pluripotent stem cells. Nature 471(7336):63-67. https://doi.org/10.1038/nature09805

Grobner SN, Worst BC, Weischenfeldt J et al (2018) The landscape of genomic alterations across childhood cancers. Nature. https://doi. org/10.1038/nature25480

Hansson O, Castilho RF, Kaminski Schierle GS et al (2000) Additive effects of caspase inhibitor and lazaroid on the survival of transplanted rat and human embryonic dopamine neurons. Exp Neurol 164(1):102-111. https://doi.org/10.1006/exnr.2000.7406

Harris G, Hogberg H, Hartung T, Smirnova L (2017) 3D differentiation of LUHMES cell line to study recovery and delayed neurotoxic effects. Curr Prot Toxicol 73:11-23 https://doi.org/10.1002/ cptx. 29

Hartung T, Leist M (2008) Food for thought ... on the evolution of toxicology and the phasing out of animal testing. ALTEX 25(2):91-102

Hirt UA, Gantner F, Leist M (2000) Phagocytosis of nonapoptotic cells dying by caspase-independent mechanisms. J Immunol 164(12):6520-6529

Hughes P, Marshall D, Reid Y, Parkes H, Gelber C (2007) The costs of using unauthenticated, over-passaged cell lines: how much more data do we need? BioTech 43(5):575-586

Kaas CS, Kristensen C, Betenbaugh MJ, Andersen MR (2015) Sequencing the CHO DXB11 genome reveals regional variations in genomic stability and haploidy. BMC Genom 16:160. https:// doi.org/10.1186/s12864-015-1391-x

Karreman C (2002) AiO, combining DNA/protein programs and oligomanagement. Bioinformatics 18(6):884-885

Kleensang A, Vantangoli MM, Odwin-DaCosta S et al (2016) Genetic variability in a frozen batch of MCF-7 cells invisible in routine authentication affecting cell function. Sci Rep 6:28994. https:// doi.org/10.1038/srep28994

Ko P, Misaghi S, Hu Z et al (2017) Probing the importance of clonality: single cell subcloning of clonally derived $\mathrm{CHO}$ cell lines yields widely diverse clones differing in growth, productivity, and product quality. Biotechnol Progress. https://doi. org/10.1002/btpr.2594

Kramer A, Green J, Pollard J Jr, Tugendreich S (2014) Causal analysis approaches in ingenuity pathway analysis. Bioinformatics 30(4):523-530. https://doi.org/10.1093/bioinformatics/btt703

Krishna A, Biryukov M, Trefois C et al (2014) Systems genomics evaluation of the SH-SY5Y neuroblastoma cell line as a model for Parkinson's disease. BMC Genom 15:1154. https:// doi.org/10.1186/1471-2164-15-1154

Krug AK, Gutbier S, Zhao L et al (2014) Transcriptional and metabolic adaptation of human neurons to the mitochondrial toxicant MPP(+). Cell Death Dis 5:e1222. https://doi.org/10.1038/cddis .2014 .166

Landry JJ, Pyl PT, Rausch T et al (2013) The genomic and transcriptomic landscape of a HeLa cell line. G3 3(8):1213-1224 https ://doi.org/10.1534/g3.113.005777

Latta M, Kunstle G, Leist M, Wendel A (2000) Metabolic depletion of ATP by fructose inversely controls CD95- and tumor necrosis factor receptor 1-mediated hepatic apoptosis. J Exp Med 191(11):1975-1985

Laurent LC, Ulitsky I, Slavin I et al (2011) Dynamic changes in the copy number of pluripotency and cell proliferation genes in human ESCs and iPSCs during reprogramming and time in culture. Cell Stem Cell 8(1):106-118. https://doi.org/10.1016/j. stem.2010.12.003

Leist M, Hasiwa N, Rovida C et al (2014) Consensus report on the future of animal-free systemic toxicity testing. ALTEX 31(3):341-356. https://doi.org/10.14573/altex.1406091

Lotharius J, Barg S, Wiekop P, Lundberg C, Raymon HK, Brundin $\mathrm{P}$ (2002) Effect of mutant alpha-synuclein on dopamine homeostasis in a new human mesencephalic cell line. J Biol Chem 277(41):38884-38894. https://doi.org/10.1074/jbc.M2055 18200

Lotharius J, Falsig J, van Beek J et al (2005) Progressive degeneration of human mesencephalic neuron-derived cells triggered by dopamine-dependent oxidative stress is dependent on the mixedlineage kinase pathway. J Neurosci 25(27):6329-6342. https://doi. org/10.1523/JNEUROSCI.1746-05.2005

Ma X, Liu Y, Liu Y et al (2018) Pan-cancer genome and transcriptome analyses of 1,699 paediatric leukaemias and solid tumours. Nature. https://doi.org/10.1038/nature25795

MacDonald JR, Ziman R, Yuen RK, Feuk L, Scherer SW (2014) The database of genomic variants: a curated collection of structural variation in the human genome. Nucleic Acids Res 42(Database issue):D986-D992. https://doi.org/10.1093/nar/gkt958

Martins-Taylor K, Xu RH (2012) Concise review: genomic stability of human induced pluripotent stem cells. Stem Cells 30(1):22-27. https://doi.org/10.1002/stem.705

McConnell MJ, Lindberg MR, Brennand KJ et al (2013) Mosaic copy number variation in human neurons. Science 342(6158):632-637. https://doi.org/10.1126/science. 1243472

Milholland B, Dong X, Zhang L, Hao X, Suh Y, Vijg J (2017) Differences between germline and somatic mutation rates in humans and mice. Nat Commun 8:15183. https://doi.org/10.1038/ncomms 15183

Miller JK, Buchner N, Timms L et al (2014) Use of Sequenom sample ID Plus(R) SNP genotyping in identification of FFPE tumor samples. PloS One 9(2):e88163. https://doi.org/10.1371/journ al.pone. 0088163

Mor DE, Tsika E, Mazzulli JR et al (2017) Dopamine induces soluble alpha-synuclein oligomers and nigrostriatal degeneration. Nat Neurosci 20(11):1560-1568. https://doi.org/10.1038/nn.4641 
Mosharov EV, Larsen KE, Kanter E et al (2009) Interplay between cytosolic dopamine, calcium, and alpha-synuclein causes selective death of substantia nigra neurons. Neuron 62(2):218-229. https:// doi.org/10.1016/j.neuron.2009.01.033

Nielsen J, Fejgin K, Sotty F et al (2017) A mouse model of the schizophrenia-associated 1q21.1 microdeletion syndrome exhibits altered mesolimbic dopamine transmission. Transl Psychiatry 7(11):1261. https://doi.org/10.1038/s41398-017-0011-8

Nims RW, Reid Y (2017) Best practices for authenticating cell lines. In vitro Cell Dev Biol Anim 53(10):880-887. https://doi. org/10.1007/s11626-017-0212-8

Pallocca G, Nyffeler J, Dolde X et al (2017) Impairment of human neural crest cell migration by prolonged exposure to interferonbeta. Arch Toxicol 91(10):3385-3402. https://doi.org/10.1007/ s00204-017-1966-1

Pamies D, Bal-Price A, Simeonov A et al (2017) Good cell culture practice for stem cells and stem-cell-derived models. Altex 34(1):95-132. https://doi.org/10.14573/altex.1607121

Poltl D, Schildknecht S, Karreman C, Leist M (2012) Uncoupling of ATP-depletion and cell death in human dopaminergic neurons. Neurotoxicology 33(4):769-779. https://doi.org/10.1016/j.neuro .2011 .12 .007

Purcell S, Neale B, Todd-Brown K et al (2007) PLINK: a tool set for whole-genome association and population-based linkage analyses. Am J Hum Genet 81(3):559-575. https://doi.org/10.1086/519795

Raczy C, Petrovski R, Saunders CT et al (2013) Isaac: ultra-fast wholegenome secondary analysis on Illumina sequencing platforms. Bioinformatics 29(16):2041-2043. https://doi.org/10.1093/bioin formatics/btt314

Ramirez T, Daneshian M, Kamp H et al (2013) Metabolomics in toxicology and preclinical research. ALTEX 30(2):209-225

Reid YA (2017) Best practices for naming, receiving, and managing cells in culture. In vitro Cell Dev Biol Anim 53(9):761-774. https ://doi.org/10.1007/s11626-017-0199-1

Reumers J, De Rijk P, Zhao H et al (2012) Optimized filtering reduces the error rate in detecting genomic variants by short-read sequencing. Nat Biotechnol 30(1):61-68. https://doi.org/10.1038/nbt.2053

Rowen L, Young J, Birditt B et al (2002) Analysis of the human neurexin genes: alternative splicing and the generation of protein diversity. Genomics 79(4):587-597. https://doi.org/10.1006/geno.2002.6734

Sarkar S, Malovic E, Harishchandra DS et al (2017) Mitochondrial impairment in microglia amplifies NLRP3 inflammasome proinflammatory signaling in cell culture and animal models of Parkinson's disease. NPJ Parkinson's Dis 3:30. https://doi.org/10.1038/ s41531-017-0032-2

Schildknecht S, Poltl D, Nagel DM et al (2009) Requirement of a dopaminergic neuronal phenotype for toxicity of low concentrations of 1-methyl-4-phenylpyridinium to human cells. Toxicol Appl Pharmacol 241(1):23-35. https://doi.org/10.1016/j.taap.2009.07.027

Schildknecht S, Karreman C, Poltl D et al (2013) Generation of genetically-modified human differentiated cells for toxicological tests and the study of neurodegenerative diseases. Altex 30(4):427444. https://doi.org/10.14573/altex.2013.4.427

Schildknecht S, Pape R, Meiser J et al (2015) Preferential extracellular generation of the active Parkinsonian toxin MPP + by transporter-independent export of the intermediate MPDP+. Antioxidants Redox Signal 23(13):1001-1016. https://doi.org/10.1089/ ars.2015.6297

Schildknecht S, Di Monte DA, Pape R, Tieu K, Leist M (2017) Tipping points and endogenous determinants of nigrostriatal degeneration by MPTP. Trends Pharmacol Sci 38(6):541-555. https://doi. org/10.1016/j.tips.2017.03.010

Scholz D, Poltl D, Genewsky A et al (2011) Rapid, complete and large-scale generation of post-mitotic neurons from the human LUHMES cell line. J Neurochem 119(5):957-971. https://doi.org $/ 10.1111 / \mathrm{j} .1471-4159.2011 .07255 . \mathrm{x}$
Scholz D, Chernyshova Y, Uckert AK, Leist M (2018) Reduced Abeta secretion by human neurons under conditions of strongly increased BACE activity. J Neurochem. https://doi.org/10.1111/ jnc. 14467

Seim I, Jeffery PL, Thomas PB, Nelson CC, Chopin LK (2017) Wholegenome sequence of the metastatic $\mathrm{PC} 3$ and $\mathrm{LNCaP}$ human prostate cancer cell lines. G3: Genes, Genom, Genet. 7(6):1731-1741 https://doi.org/10.1534/g3.117.039909

Stacey G (2012) Sourcing and using stem cell lines for radiation research: potential, challenges and good stem cell culture practice. Int J Radiat Biol 88(10):703-708. https://doi.org/10.3109/09553 002.2012 .714518

Stacey G (2017) Stem cell banking: a global view. Methods Mol Biol 1590:3-10. https://doi.org/10.1007/978-1-4939-6921-0_1

Stefansson H, Meyer-Lindenberg A, Steinberg S et al (2014) CNVs conferring risk of autism or schizophrenia affect cognition in controls. Nature 505(7483):361-366. https://doi.org/10.1038/ nature 12818

Stiegler NV, Krug AK, Matt F, Leist M (2011) Assessment of chemical-induced impairment of human neurite outgrowth by multiparametric live cell imaging in high-density cultures. Toxicol Sci 121(1):73-87. https://doi.org/10.1093/toxsci/kfr034

Szego EM, Gerhardt E, Outeiro TF (2017) Sirtuin 2 enhances dopaminergic differentiation via the AKT/GSK-3beta/beta-catenin pathway. Neurobiol Aging 56:7-16. https://doi.org/10.1016/j. neurobiolaging.2017.04.001

Terron A, Bal-Price A, Paini A et al (2018) An adverse outcome pathway for parkinsonian motor deficits associated with mitochondrial complex I inhibition. Arch Toxicol 92(1):41-82. https://doi. org/10.1007/s00204-017-2133-4

Volbracht C, Leist M, Nicotera P (1999) ATP controls neuronal apoptosis triggered by microtubule breakdown or potassium deprivation. Mol Med 5(7):477-489

Volbracht C, Leist M, Kolb SA, Nicotera P (2001) Apoptosis in caspase-inhibited neurons. Mol Med 7(1):36-48

Wang K, Li M, Hakonarson H (2010) ANNOVAR: functional annotation of genetic variants from high-throughput sequencing data. Nucleic Acids Res 38(16):e164. https://doi.org/10.1093/nar/gkq60 3

Xiang W, Schlachetzki JC, Helling S et al (2013) Oxidative stressinduced posttranslational modifications of alpha-synuclein: specific modification of alpha-synuclein by 4-hydroxy-2-nonenal increases dopaminergic toxicity. Mol Cell Neurosci 54:71-83. https://doi.org/10.1016/j.mcn.2013.01.004

Yang X, Xu S, Consortium HP-AS, Indian Genome Variation C (2011) Identification of close relatives in the HUGO Pan-Asian SNP database. PloS One 6(12):e29502. https://doi.org/10.1371/journ al.pone. 0029502

Youssoufian H, Pyeritz RE (2002) Mechanisms and consequences of somatic mosaicism in humans. Nat Rev Genet 3(10):748-758. https://doi.org/10.1038/nrg906

Zhang XM, Yin M, Zhang MH (2014) Cell-based assays for Parkinson's disease using differentiated human LUHMES cells. Acta pharmacologica Sinica 35(7):945-956. https://doi.org/10.1038/ aps.2014.36

Zimmer B, Kuegler PB, Baudis B et al (2011a) Coordinated waves of gene expression during neuronal differentiation of embryonic stem cells as basis for novel approaches to developmental neurotoxicity testing. Cell Death Differ 18(3):383-395. https://doi.org/10.1038/ cdd.2010.109

Zimmer B, Schildknecht S, Kuegler PB, Tanavde V, Kadereit S, Leist M (2011b) Sensitivity of dopaminergic neuron differentiation from stem cells to chronic low-dose methylmercury exposure. Toxicol Sci 121(2):357-367. https://doi.org/10.1093/toxsci/kfr054 